\title{
A volume element model (VEM) for energy systems engineering
}

\author{
E. Dilay ${ }^{1}$, J. V. C. Vargas ${ }^{1, *, \dagger}$, J. A. Souza ${ }^{2}$, J. C. Ordonez ${ }^{3}$, S. Yang ${ }^{3}$ and A. B. Mariano ${ }^{1}$ \\ ${ }^{1}$ Departamento de Engenharia Mecânica, Programa de Pós-Graduação em Engenharia e Ciência de Materiais (PIPE) e Núcleo de \\ Pesquisa e Desenvolvimento em Energia Auto-Sustentável (NPDEAS), Universidade Federal do Paraná (UFPR), CP 19011, 81531-980, \\ Curitiba, PR, Brazil \\ ${ }^{2}$ Escola de Engenharia, Universidade Federal do Rio Grande (FURG), Av. Itália, km 08 S/N, Campus Carreiros, 96201-900, Rio Grande, \\ RS, Brazil \\ ${ }^{3}$ Department of Mechanical Engineering, Energy and Sustainability Center, and Center for Advanced Power Systems, Florida State \\ University, Tallahassee, FL 32310-6046, USA
}

\section{SUMMARY}

This work presents a simplified modeling and simulation approach for energy systems engineering that is capable of providing quick and accurate responses during system design. For that, the laws of conservation are combined with available empirical and theoretical correlations to quantify the diverse types of flows that cross the system and produce a simplified tridimensional mathematical model, namely a volume element model (VEM). The physical domain of interest is discretized in space, thus producing a system of algebraic and ODEs with respect to time, whose solution delivers the project variables spatial distribution and dynamic response. In order to illustrate the application of the VEM in energy systems engineering, three example problems are considered: (i) a regenerative heat exchanger; (ii) a power electronic building block (PEBB); and (iii) a notional all-electric ship. The same mathematical model was used to analyze problems (ii) and (iii), that is, the thermal management of heat-generating equipment packaging. In the examples, the converged mesh had a total of 20, 2000, and 7725 volume elements. The third problem led to the largest simulation, which for steady-state cases took between 5 and $10 \mathrm{~min}$ of computational time to reach convergence and for the ship dynamic response $50 \mathrm{~min}$ (i.e., 80,000 s of real time). The regenerative heat exchanger model demonstrated how VEM allowed for the coexistence of different phases (subsystems) within the same volume element. The thermal management model was adjusted and experimentally validated for the PEBB system, and it was possible to perform a parametric and dynamic analysis of the PEBB and of the notional all-electric ship. Therefore, because of the observed combination of accuracy and low computational time, it is expected that the model could be used as an efficient tool for design, control, and optimization in energy systems engineering. Copyright () 2014 John Wiley \& Sons, Ltd.

\section{KEY WORDS}

species concentration; temperature field; relative humidity field; thermal management; early-stage design tool; model adjustment; model experimental validation

\section{Correspondence}

*J. V. C. Vargas, Departamento de Engenharia Mecânica, Programa de Pós-Graduação em Engenharia e Ciência de Materiais (PIPE) e Núcleo de Pesquisa e Desenvolvimento em Energia Auto-Sustentável (NPDEAS), Universidade Federal do Paraná (UFPR), CP 19011, 81531-980, Curitiba, PR, Brazil.

†E-mail: jvargas@demec.ufpr.br

Received 3 March 2014; Accepted 12 April 2014

\section{INTRODUCTION}

Mathematical modeling, simulation, and thermodynamic optimization approaches are utilized in systems engineering in order to increase system energy efficiency and to reduce costs and environmental impact. However, design and parametric optimization of a system or a set of systems working together for maximum performance (e.g., minimum entropy generation, maximum energy efficiency, and maximum power output) requires the analysis, or simulation, of a variety of possible system configurations each representing a different set of operating parameters.

Systems engineering is an interdisciplinary field of engineering focusing on the development of complex artificial systems [1,2]. One definition of systems engineering from the International Council of Systems Engineering 
states that 'systems engineering is an interdisciplinary approach to construct systems of high complexity. It focuses on defining customer needs and required functionality early in the development cycle, documenting requirements, and then proceeding with design synthesis and system validation while considering the complete problem' [3].

Systems engineering techniques are used, for example, from sophisticated spacecraft designs to electronic chips and from robotics to software creation for building bridges. Systems engineering uses a set of tools including modeling and simulation [2]. Some examples of systems engineering include commercial or military ships, airplanes, oil refinery, power plants, and similar processes involving bioenergy in which living organisms must interact with machines in order to fulfill the purpose that benefits the human society.

Based on the previous definition, it is evident that engineering systems become more complex as the society evolves. The multidisciplinary aspects of system components possesses challenges to the designer, and the cost of building prototypes that may not work must be saved. In that scenario, the simulation tool emerges as a way to enable development and analysis of an enterprise before the financial investment is made. However, even the most advanced computers have a finite processing capacity, which restricts the simulation scale. Hence, determining the degree of complexity of a mathematical model of a system is a critical task in systems engineering.

In general, mathematical models are adopted in system or component level [1,2]. In the literature, different denominations are given to these two levels: (i) qualitative modeling, that is, which captures accurately system response trends, but with low accuracy in local and absolute variables, and quantitative modeling, that is, capturing accurate system response trends and local variables [4,5]; (ii) high order and low order, as described by Shapiro [6]; and (iii) concentrated and distributed modeling [7,8]. A summary of these classifications is shown in Table I.

A simulation in systems engineering must evaluate how several sets of operating and design parameters affect the system performance. Optimization might be impossible if too much computational time is required to evaluate the system. Shapiro cites, in case of electronic packaging, for example, that there is a need to reduce the size of heat transfer simulations in order to analyze more complex

Table I. Classification of mathematical model types.

\begin{tabular}{llc}
\hline $\begin{array}{l}\text { Models with local } \\
\text { variables of } \\
\text { low precision }\end{array}$ & $\begin{array}{c}\text { Models with local } \\
\text { variables of } \\
\text { high precision }\end{array}$ & Reference \\
\hline Qualitative & Quantitative & {$[4,5]$} \\
Concentrated & Distributed & {$[7,8]$} \\
System & Component & {$[1,2]$} \\
Low order & High order & {$[6]$} \\
\hline
\end{tabular}

cases and additional physical phenomena without losing significant precision and thus reduce the size of electronic devices [6]. In cited cases, the reduced-order model decreases the system response precision by only $5 \%$, which does not affect the evaluation in its early-stage design. It is also important to benefit from empirical correlations for complex situations (for instance, to analyze turbulent flows through complex geometries).

The models must be able to perform a combined parametric search. In case of the simulation that takes a day to complete and there are 10 parameters of interest with five values for each parameter, it will take 267 years to simulate only $1 \%$ of the entire system, that is,

$$
N_{\text {years }}=\frac{5^{10}}{100} \text { days } \times \frac{1}{365} \frac{\text { years }}{\text { days }}=267 \text { years. }
$$

For the same case, if the simulation takes a second to finish, it will take about a day to complete, which is an acceptable time [6].

High-order models take into account more phenomena than the low-order ones and generally use partial differential equations of higher order. That is where the denomination high order comes from [6]. Because of the very nature of modeling, the more complete models are, the higher accuracy they show. On the other extreme, low-order models contain partial or ODEs of low order (based on the highest-order derivative of the unknown function).

Model reduction, as shown in Figure 1, is a process that takes a large model of high order and reduces its size while maintaining most of its precision. This process can be illustrated with a vibrating membrane model such as a drum. In this case, the response position and phase of a membrane can be represented by the first few modes of vibration without affecting its precision. These first vibration modes are natural, that is, dominant; therefore, the rest of the vibration modes contribute little to the overall system response and can be neglected [6].

Another way to obtain a reduced-order model is to start from a low-order model and experimentally identify the missing parts. This process is also known as experimental

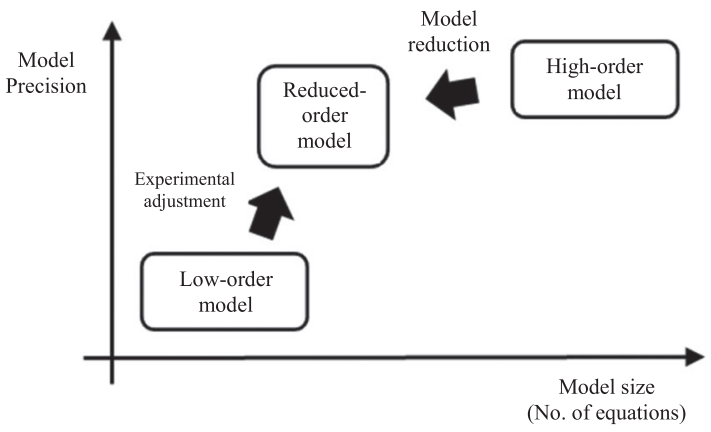

Figure 1. Relationship between precision and size of the mathematical model [6]. 
adjustment, which can be performed through the inverse problem of parameter estimation (IPPE) that aims to minimize the difference between numerical and experimental results. Similarly, a reduced-order model (good precision and reasonable size) can be derived either from a high-order model (high precision and large in size) or from a low-order model (small and low precision).

Numerous works in the technical literature could be cited in order to illustrate the need for a mathematical model appropriate for systems engineering, but in this brief review, only a few representative studies are discussed. However, the discussion could be generalized for any application in systems engineering, as the complexity and diversity aspects of components and processes at the local level-acting together to produce a system response at the system global level-are present in any system.

In electronics, for example, thermomechanical stresses are known to damage electronic devices, and this can be analyzed solely with the knowledge of the temperature gradient for the equipment. As a result, methodologies to predict the need for a repair or replacement prior to the equipment's failure became necessary, and several approaches have been proposed using the FEM. Consequently, it is possible to calculate beforehand the possible damage in electronic devices due to cyclic thermal and thermomechanical loads $[9,10]$. Bagnoli et al. [11] proposed an analytical solution to substitute expensive FEM software, but the strategy is applicable only for steady-state processes in notional structures of two layers. Yang and Chen [12] conducted an experimental investigation to test dynamic behavior of electronic packaging, but only considering a fixed and reliable design. This created the need for precise mathematical models and low computational time. The principal message of all these studies is that the community of production systems and electronic packaging seeks to reduce the simulation time in structural and heat transfer analyses.

Thermal response in systems engineering was investigated by means of simple physical models in previous studies [5,13-16] of electronic packaging and all-electric ships. In these models, the domain of interest (system under consideration) was initially discretized in three dimensions using a cell-centered finite-volume scheme, and principles of classical thermodynamics and heat transfer were applied to each cell, resulting in a system of ODEs with respect to time. Empirical and analytical correlations available to calculate required physical quantities, such as friction and heat transfer coefficients, were used to quantify the energy transfer between cells. Convergence was obtained with sparse meshes and low computational time to obtain solutions (i.e., temperature and relative humidity) with respect to time and space. The scheme was named volume element model (VEM) [5] and was characterized as a three-dimensional dynamic reduced-order model.

Song et al. [17] argued that the thermal modeling of data centers, including the prediction of temperature and air flow distributions, was an extremely demanding process in terms of simulation time using CFD, which motivated the use of reduced-order models in their study to determine the cooling requirement in real time. The authors developed a three-dimensional zonal model, validating it by a direct comparison with results obtained using the finite-volume scheme for the system operating under the same conditions, i.e., data center. Numerical results of the zonal model showed an agreement within $10 \%$ compared with those obtained using CFD, with the advantage of reduced computational time.

Results obtained by Song et al., as well as several other related studies [18-20], show that zonal models can be established as design tools for effective real-time thermal management [17]. However, unlike the VEM [5], which is also a reduced-order model, zonal models require connection of cells and interfaces, which must be performed manually in an elaborate form, requiring a skilled analyst [17]. Moreover, such zonal models need to know the flow field beforehand, which can be extrapolated from experimental measurements or from previously obtained CFD solutions.

In summary, according to the literature review, mathematical modeling techniques are mature, precise, and robust for components at the local level. However, at the global level in systems engineering, the problem becomes complex, and the state-of-the-art techniques are not as advanced as those for the component-level analysis. Hence, modeling, simulation, and optimization approaches in systems engineering still remain as challenges to overcome. To address this challenge, this paper presents a method for compact mathematical modeling for dynamic simulations in systems engineering, focusing on its implementation for early-stage design, optimization, and potential use in controls. The proposed method combines existing techniques in an effort to produce a reduced-order model, that is, an intermediate between low-order and high-order models, while maintaining sufficient accuracy to serve as an effective design analysis tool.

\section{MATHEMATICAL MODEL}

The flowchart shown in Figure 2 illustrates a method that has been widely used to model dynamic engineering systems [4,5]. The first step is the selection of a modeling strategy to adopt (high order: space and time dependent; low order: time dependent only; or reduced order: intermediate model) and identification of the physical system under consideration (existing or theoretical). In stage 2, a synthesis is conducted, in which simplified assumptions are adopted in order to minimize the mathematical complexity of the model, while conserving the main physical phenomena responsible for the process or equipment operation. In stage 3 , a mathematical model is derived based on the physical laws that govern the system, and on the assumptions, resulting in a system of algebraic and ODEs or partial differential equations. In stage 4, unknown variables and parameters in the 


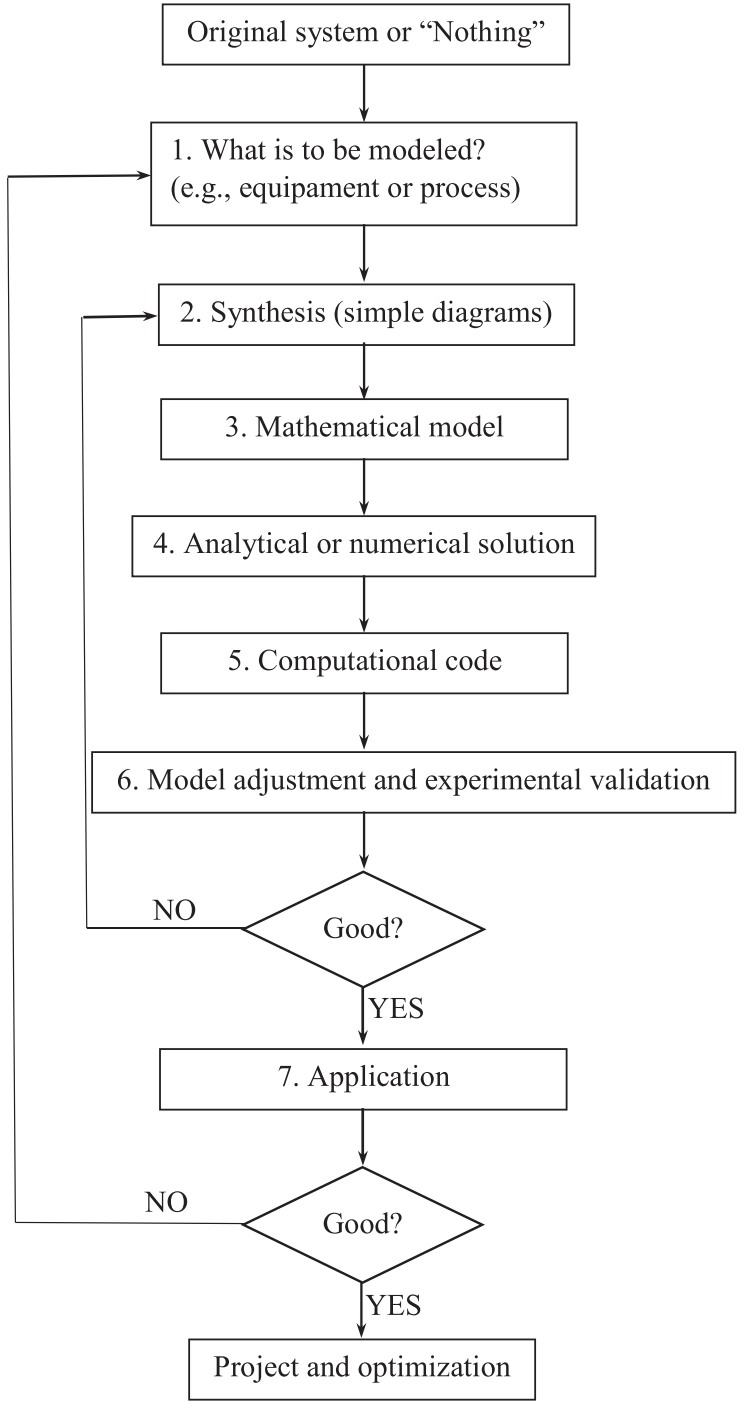

Figure 2. Flowchart for modeling and simulation of physical systems $[4,5]$.

mathematical model are identified and verified if there is an analytical solution and, if not, decide which numerical method to use in order to obtain the solution. In stage 5, a decision is made on which computer code is to be employed to implement the numerical method, which can be one's own code or an existing software. Stage 6 performs the model adjustment and experimental validation, which allows one to evaluate how precise the results could be, so that the model could be used as a practical engineering tool. Stage 7 consists of applying the model and verifying if the equipment or process complies with the proposed objectives, and if not, the system must be reconsidered, and a new model needs to be derived.

In general, the mathematical model helps to simulate response or behavior of a real system on a computer, allowing the calculation of the time and space distribution of any physical quantity in an engineering system under consideration (e.g., temperature, relative humidity, and concentration of species), that is, according to nonequilibrium thermodynamics $[21,22]$. These distributions are determined based on ambient conditions, fluid flow, system geometry, and internal sources.

The model described in this paper provides a general method for applications in systems engineering. The method is based on the VEM, initially proposed by Vargas et al. [4] for effective thermal management in cooling of electronic devices, which is generalized for its use in diverse problems including, but not limited to, thermal analysis and other phenomena like mass transport across volume elements (VEs). The governing equations are the conservation of mass, energy, and species applied to each VE.

The method proposed for items 3,4 , and 5 in the flowchart shown in Figure 2 is therefore summarized in three main stages:

1. Discretization: The system domain is divided into VEs (control volumes), which are cell-centered finite volumes that may contain solid, fluid, or both as subsystems in the cell interior [23]. As a result, the spatial dependence of the system is incorporated into the model.

2. Mathematical model: Initially, the velocity field in the system domain is formulated through algebraic equations derived from the conservation of mass and momentum principles, and using empirical and theoretical correlations if available. Consequently, an ODE with respect to time is derived to calculate the quantity of interest in each volume center, with the following examples: (i) in case of temperature, this is performed with the first law of thermodynamics (energy conservation principle), and (ii) to calculate the concentration of a substance in the center of each volume in a mixture, the procedure is analogous, establishing an ODE for each chemical or biological species and applying the conservation of species principle. Energy and mass transfers between VEs under consideration and with each immediate neighbor are established by empirical correlations (valid from laminar to turbulent regimes). The result is a system of ODEs for physical quantities of interest as a function of time.

3. Numerical solution: An appropriate numerical method needs to be selected and implemented using computational codes based on the mathematical model to obtain numerical results.

The VEM can be classified as a local method, where basic functions are nonzero only on that subdomain. On the other hand, global methods use basic functions that are nonzero in the entire analysis domain [23].

Based on the VEM description, it is possible to point out differences from other local numerical methods, for example, finite difference, finite element, and finite volume [23]. In these methods, partial differential equations are 
first written for physical quantities of interest with respect to space and time. Then the space is discretized, resulting in a system of ODEs in time that can be solved using any numerical method for ODEs of the author's choice.

The novelty of the present model is that the size of VEs (control volumes) does not need to be small to obtain numerical stability and sufficient precision unlike other local methods (e.g., finite difference, finite element, and finite volume). This is an advantage especially in the presence of a wide variety of solid materials, air, water, and other fluids interacting in the solution domain, since spatial derivatives are not used. Furthermore, a VE is capable of containing a mixture of solid and fluid components. In this case, physical properties of the element are calculated as a weighted average of different component properties of an element. As a result, the advantage is the ability to obtain the convergence with a low number of VEs and, thus, reduced computational time.

Additionally, mesh elements belonging to a component could be, for instance, cooled with circulating fluid, that is, cooling loops with water or other fluids could be represented inside the mesh, which consist in major differences compared with other modeling methods. Similarly, solid walls or interfaces are represented inside the mesh, unlike the zonal method [19].

\subsection{General model}

The description of a generalized mathematical model begins with Figure 3 where a typical VE (or cell) is shown, which may contain either fluid and solid materials or a combination of these two. Each element interacts with other neighboring elements, through various changing quantities. The symbols $\dot{\mathrm{G}}_{\mathrm{e}}, \dot{\mathrm{G}}_{\mathrm{w}}, \dot{\mathrm{G}}_{\mathrm{t}}, \dot{\mathrm{G}}_{\mathrm{b}}, \dot{\mathrm{G}}_{\mathrm{n}}$, and $\dot{\mathrm{G}}_{\mathrm{s}}$ represent changing rates of physical quantities under analysis with respect to time and by east, west, top, bottom, north, and south faces, respectively. These physical properties can

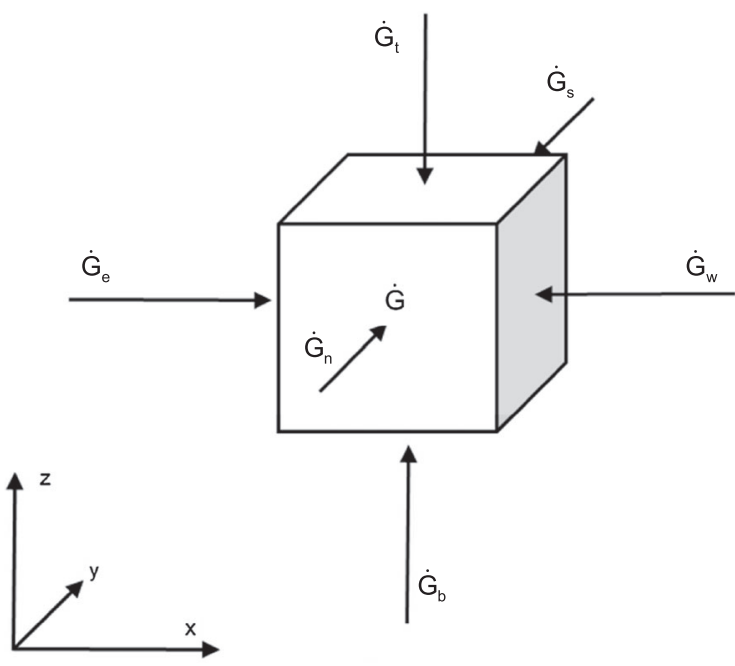

Figure 3. Typical volume element interacting with its neighbors and the source term. be mass, heat, or any other variable of interest. The term $\dot{\mathrm{G}}$ is a source term in the transport equation, which can be used to represent phenomena like heat generation, flow resistance, mass transfer between phases, and formation or degradation of a substance in a chemical reaction.

Conservation equations (e.g., mass, energy, and species) can be written for a generic scalar field $\phi$, in lumped form for each VE $\mathrm{i}$, as

$$
\frac{\mathrm{d}(\rho \mathrm{V} \phi)_{\mathrm{i}}}{\mathrm{dt}}=\sum_{\mathrm{j}=\mathrm{e}, \mathrm{w}, \mathrm{t}, \mathrm{b}, \mathrm{n}, \mathrm{s}} \dot{\mathrm{G}}_{\mathrm{j}, \mathrm{i}}+\dot{\mathrm{G}}_{\mathrm{i}}
$$

where $\mathrm{t}$ is time, $\rho$ density, $\mathrm{V}$ volume, and the rate $\dot{\mathrm{G}}_{\mathrm{j}, \mathrm{i}}$ is divided into two contributions such that

$$
\dot{\mathrm{G}}_{\mathrm{j}, \mathrm{i}}=\dot{\mathrm{G}}_{\mathrm{adv}, \mathrm{j}, \mathrm{i}}+\dot{\mathrm{G}}_{\mathrm{dif}, \mathrm{j}, \mathrm{i}}
$$

In this case, $\dot{\mathrm{G}}_{\mathrm{adv}, \mathrm{j}, \mathrm{i}}$ represents advective terms, and $\dot{\mathrm{G}}_{\mathrm{dif}, \mathrm{j}, \mathrm{i}}$ represents diffusive terms (or conductive). Radiation and other possible types of interaction, if any, are included in the diffusion equation.

Consequently Eqn. (1) is separated into the following equations:

$$
\begin{gathered}
\dot{\mathrm{G}}_{\mathrm{adv}, \mathrm{j}, \mathrm{i}}=\alpha_{\mathrm{j}, \mathrm{i}}\left(\dot{\mathrm{m}}_{\mathrm{E}, \mathrm{j}} \phi_{\mathrm{j}}-\dot{\mathrm{m}}_{\mathrm{S}, \mathrm{j}} \phi_{\mathrm{i}}\right) \\
\dot{\mathrm{G}}_{\mathrm{dif}, \mathrm{j}, \mathrm{i}}=\dot{\mathrm{G}}_{\mathrm{other}, \mathrm{j}, \mathrm{i}}+\mathrm{A}_{\mathrm{j}} \Gamma_{\mathrm{j}}^{\phi}\left(\phi_{\mathrm{j}}-\phi_{\mathrm{i}}\right) \\
\dot{\mathrm{G}}=\frac{\mathrm{V}_{\mathrm{i}}}{\mathrm{c}_{\mathrm{i}}} \mathrm{S}^{\phi} \mathrm{j}=\mathrm{e}, \mathrm{w}, \mathrm{t}, \mathrm{b}, \mathrm{n}, \mathrm{s}
\end{gathered}
$$

Equation (3) represents the advection transient behavior of variable $\phi$ across $\mathrm{VE} i$, and note that the inlet and outlet mass flow rates, $\dot{m}_{E, j}$ and $\dot{m}_{S, j}$ could be specified across the same face $\mathrm{j}$, if applicable. Mass flow rates must be estimated from the velocity field in the system domain, which is obtained from algebraic equations derived from the principles of mass and momentum conservations and with empirical and theoretical correlations if available. Note also that the quantity $\varphi$ enters VE $i$ with the value that is brought from the neighboring element in contact with face $\mathrm{j}$, or a prescribed input value, and outputs a calculated value for $\mathrm{VE} i$. In the ratio of parameters $\alpha_{j, i}=c_{j} / c_{i}, c_{j}$ (e.g., specific heat) corresponds to the substance crossing VE $i$, and $c_{i}$ is the group of substances that constitutes VE $i$.

Equation (4) is the balance of diffusive terms. Heat transfer by radiation on the face $\mathrm{j}$, if exists, is included in this term as $\dot{\mathrm{G}}_{\text {other, } \mathrm{j}, \mathrm{i}}=\dot{\mathrm{G}}_{\mathrm{rad}, \mathrm{j}, \mathrm{i}}$ and calculated depending on each particular situation. The term $\dot{\mathrm{G}}_{\mathrm{other}, \mathrm{j}, \mathrm{i}}$ is capable of including new interaction terms if needed.

Finally, Eqn. (5) refers to the source term, $S^{\phi}$, which is responsible for accommodating the remaining terms according to the physical problem under consideration. The source term represents, for example, the internal heat generation, $\dot{\mathrm{Q}}_{\mathrm{gen}, \mathrm{i}}$ when $\phi$ refers to temperature. In case of conservation of species, the term $S^{\phi}$ is a conversion rate from one species to another. 
Table II lists the values for $\phi, \mathrm{c}_{\mathrm{i}}, \mathrm{c}_{\mathrm{j}}, \Gamma^{\phi}$, and $\mathrm{S}^{\phi}$, along with Eqns. (3-5) to account for conservation of mass, energy, and species.

In Table II, $\mathrm{T}$ is the temperature; $\mathrm{Y}_{\mathrm{q}}=\mathrm{m}_{\mathrm{q}} / \mathrm{m}_{\mathrm{T}}$ is the mass fraction, in which $\mathrm{m}_{\mathrm{q}}$ is the mass of species $\mathrm{q}$ in a mixture with the total mass $\mathrm{m}_{\mathrm{T}} ; \mathrm{Y}_{1}$ is the mass fraction of species 1 with respect to all the others that are linked; $\mathrm{R}_{\mathrm{q}}$ is the stoichiometric ratio of consumption of species $\mathrm{q}$ as a function of conversion rate of species 1 , noting that $R_{1}=1 ; \mu$ is the reaction rate; $U_{j}$ is the overall heat transfer coefficient between $\mathrm{VE} \mathrm{j}$ and the neighbor $\mathrm{VE} \mathrm{i} ; \mathrm{D}_{\mathrm{q}}$ is the mass diffusivity of species $\mathrm{q}$ in a mixture, and $l_{i, j}$ is the distance between two VE centers, $i$ and the adjacent $j$. Figure 4 shows the balance for the variable $\phi$ for a one-dimensional discretization. Highlighted are advective and diffusive fluxes being transported across VE i.

Equations (1)-(5) and Table II give a general form of a VEM.

This means that the system under consideration could be modeled for different physical phenomena through Eqn. (1), by taking into account the appropriate coefficients in Table II.

For example, the mass balance for the system under consideration can be obtained using Eqn. (1) and taking the coefficients in the first line of Table II. Consequently, this procedure results in the following equation:

$$
\frac{\mathrm{d}(\rho \mathrm{V})_{\mathrm{i}}}{\mathrm{dt}}=\sum_{\mathrm{j}=\mathrm{e}, \mathrm{w}, \mathrm{t}, \mathrm{b}, \mathrm{n}, \mathrm{s}}\left(\dot{\mathrm{m}}_{\mathrm{E}, \mathrm{j}}-\dot{\mathrm{m}}_{\mathrm{S}, \mathrm{j}}\right)
$$

which is the conservation of mass equation.

The same procedure, but taking the second row in Table II (conservation of energy), results in

$$
\begin{aligned}
\frac{d(\rho V T)_{i}}{d t}= & \sum_{j=e, w, t, b, n, s} \frac{c_{j}}{c_{i}}\left(\dot{m}_{E, j} T_{j}-\dot{m}_{S, j} T_{i}\right) \\
& +\sum_{j=e, w, t, b, n, s} A_{j} \frac{U_{j}}{c_{i}}\left(T_{j}-T_{i}\right)+\frac{\dot{Q}_{g e n, i}}{c_{i}}
\end{aligned}
$$

or in a simplified form

$$
\frac{\mathrm{dT}_{\mathrm{i}}}{\mathrm{dt}}=\frac{1}{(\rho \mathrm{Vc})}\left(\sum_{\mathrm{j}=\mathrm{e}, \mathrm{w}, \mathrm{t}, \mathrm{b}, \mathrm{n}, \mathrm{s}} \dot{\mathrm{Q}}_{\mathrm{j}, \mathrm{i}}+\dot{\mathrm{Q}}_{\mathrm{gen}, \mathrm{i}}\right)
$$

which represents the conservation of energy equation applied to VE i, with convection, conduction, and generation terms. Repeating the same process for species $\mathrm{q}$ in a mixture, an equation in terms of mass fraction, $\mathrm{Y}_{\mathrm{q}}$, is obtained:

$$
\begin{aligned}
\frac{\mathrm{d}\left(\rho \mathrm{VY} \mathrm{Y}_{\mathrm{q}}\right)_{\mathrm{i}}}{\mathrm{dt}}= & \sum_{\mathrm{j}=\mathrm{e}, \mathrm{w}, \mathrm{t}, \mathrm{b}, \mathrm{n}, \mathrm{s}}\left(\dot{\mathrm{m}}_{\mathrm{E}, \mathrm{j}} Y_{\mathrm{q}, \mathrm{j}}-\dot{\mathrm{m}}_{\mathrm{S}, \mathrm{j}} \mathrm{Y}_{\mathrm{q}, \mathrm{i}}\right) \\
& +\sum_{\mathrm{j}=\mathrm{e}, \mathrm{w}, \mathrm{t}, \mathrm{b}, \mathrm{n}, \mathrm{s}} \mathrm{A}_{\mathrm{j}} \frac{\rho \mathrm{D}_{\mathrm{q}}}{\mathrm{l}_{\mathrm{i}, \mathrm{j}}}\left(\mathrm{Y}_{\mathrm{q}, \mathrm{j}}-\mathrm{Y}_{\mathrm{q}, \mathrm{i}}\right) \\
& +\rho \mathrm{V}_{\mathrm{i}} \mathrm{Y}_{1} \mu \mathrm{R}_{\mathrm{q}}
\end{aligned}
$$

The system of ODEs defined by Eqn (1), with given initial conditions $\phi_{i}, 0$, formulates an initial value problem (IVP) to be solved. The solution to the IVP determines the general scalar field inside the domain at any given time.

\subsection{Element types and their interactions}

The VEM allows three element types to coexist in an integrated form within the same region of the computational domain: solid, fluid, and mixture (solid + fluid) as shown in Figure 5.

Table II. Values for Eqns. (3-5).

\begin{tabular}{lccccc}
\hline Conservation equations & $\phi$ & $c_{i}$ & $c_{j}$ & $\Gamma^{\phi}$ & $S^{\phi}$ \\
\hline Mass & 1 & 1 & 1 & 0 & 0 \\
Energy & $T$ & $c_{i}$ & $c_{j}$ & $U_{j} / c_{i}$ & $\dot{Q}_{\text {gen, },} / V_{i}$ \\
Mass fraction of species $q$ & $Y_{q}$ & 1 & 1 & $\rho D_{q} / l_{i, j}$ & $e . g ., \rho Y_{1} \mu R_{a}$ \\
\hline
\end{tabular}

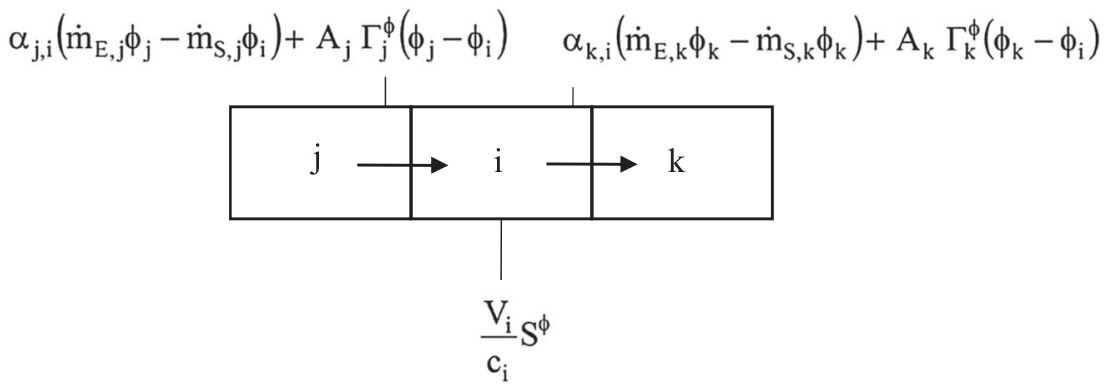

Figure 4. Balance of variable $\phi$ for one-dimensional discretization in volume element $\mathrm{i}$. 

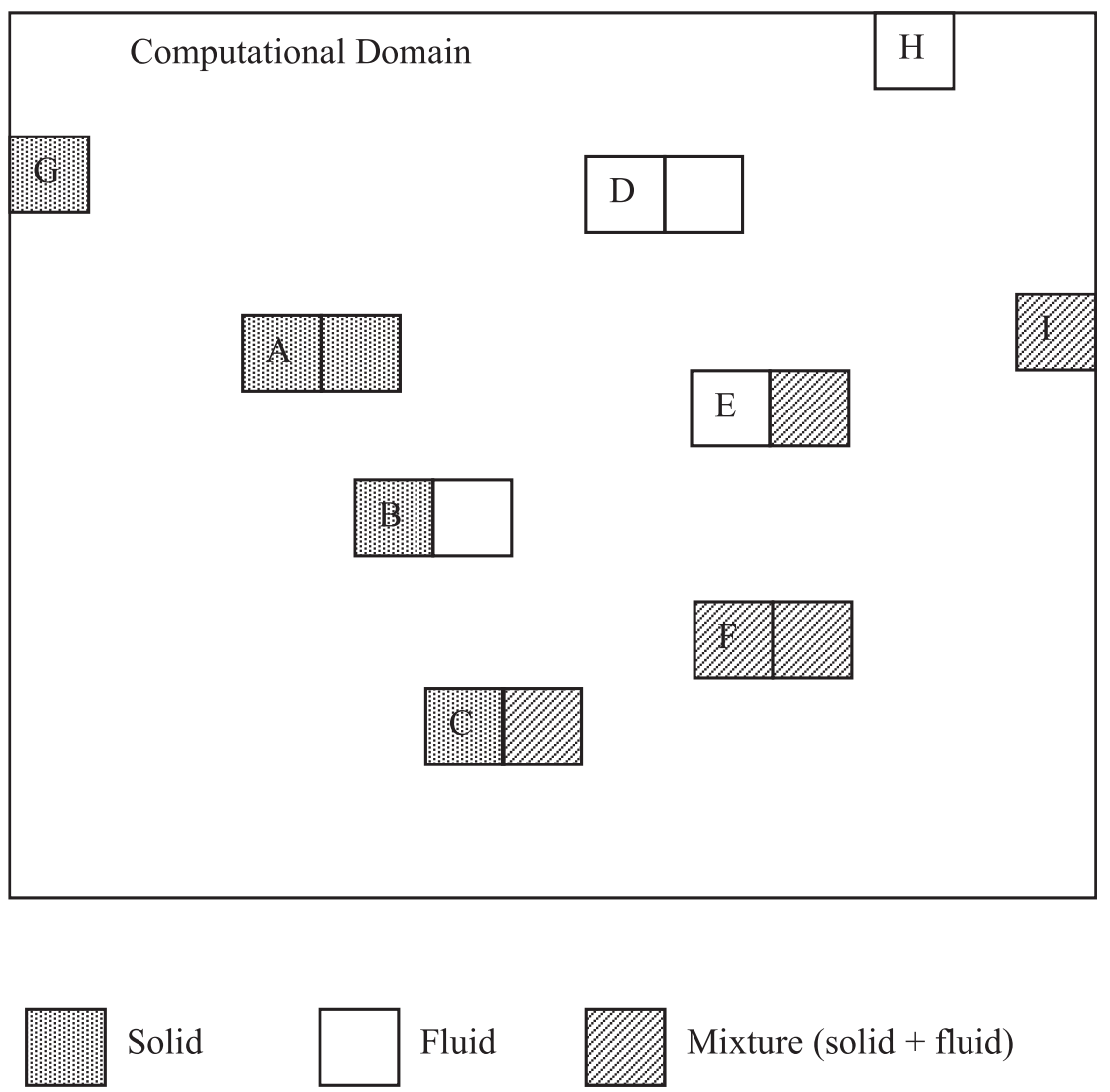

Figure 5. Volume element types and their possible interactions.

All possible interactions between each VE need to be established for different element types. According to Figure 5, the following interactions are possible:
A. VE solid and solid
B. VE solid and fluid
C. VE solid and mixture
D. VE fluid and fluid
E. VE fluid and mixture
F. VE mixture and mixture

Additionally, there exist three possible interactions with the boundary of the computational domain, that is,

G. VE solid and boundary

H. VE fluid and boundary

I. VE mixture and boundary

Appropriate equations must be written for each possible interaction type. In this case, Eqns. (1)-(5) and coefficients from Table II are utilized.

At this point, it is important to highlight a particular characteristic of the VEM compared with other methods. In case of mixed VE, VEM has two alternatives that can be used in a separate or combined manner for the same model:
1. Treat VE contents as a homogeneous mixture of entities (substances), calculating uniform properties for the VE using a weighted average proportional to the mass of each entity (substance) or

2. Treat VE contents as a group of distinct entities, defining a subsystem for each and applying Eqn. (1) separately separately to each. In this case, for each VE, there will be a number of ODEs equal to the number of subsystems defined for the VE under analysis.

The general description of the VEM ends at this point and does not include the details of the specific theoretical treatment of each application. In this way, the possibility of different mathematical models according to the decision and creativity of the modeler is recognized, searching for system mathematical representations that are as close as possible to the physical reality. In the next section, three energy systems engineering examples are analyzed with the objective of demonstrating the practical application of the VEM.

\section{APPLICATIONS}

In order to illustrate the application of the VEM in energy systems engineering, the following problems were 
considered: (i) a regenerative heat exchanger; (ii) a power electronic building block (PEBB); and (iii) a notional allelectric ship.

\subsection{Regenerative heat exchanger}

Figure 6 shows a schematic diagram of a counterflow regenerative heat exchanger. The mass and energy conservation principles are applied to the system in order to derive the mathematical model.

Initially, the equipment is divided into VEs. Figure 7 illustrates how each VE is of a mixed type (solid + fluid). In this particular system, it is important to distinguish the temperature of each entity present inside each VE to characterize the functionality and performance of the equipment. Therefore, the second alternative of VEM for mixed elements is used, that is, divide each VE into three subsystems as follows:

Subsystem 1: regenerator grid and tube (solid portion) Subsystem 2: hot fluid flow

Subsystem 3: innermost fluid flow
The next step is to mathematically model each subsystem inside the VE shown in Figure 7. In this analysis, principles of mass and energy conservation are used in a combined form, to quantify energetic interactions between all subsystems using appropriate equations. Fourier's law for heat conduction and Newton's law for convection are used. The regenerative heat exchanger model was originally presented by Martins et al. [24], considering subsystems 1, 2 , and 3 for each VE and assuming the external walls were adiabatic. In this study, the heat leakage through the external walls is taken into account. The mathematical model derived from Eqn. (1) is applied to each subsystem inside the VE, which takes the form of conservation of energy, that is, the first law of thermodynamics.

Subsytem 1. regenerator grid and tube (solid portionblack in Figure 7)

Assumptions:

1. Grid is welded with inner tube.

2. Grid has no physical contact with the outer tube.

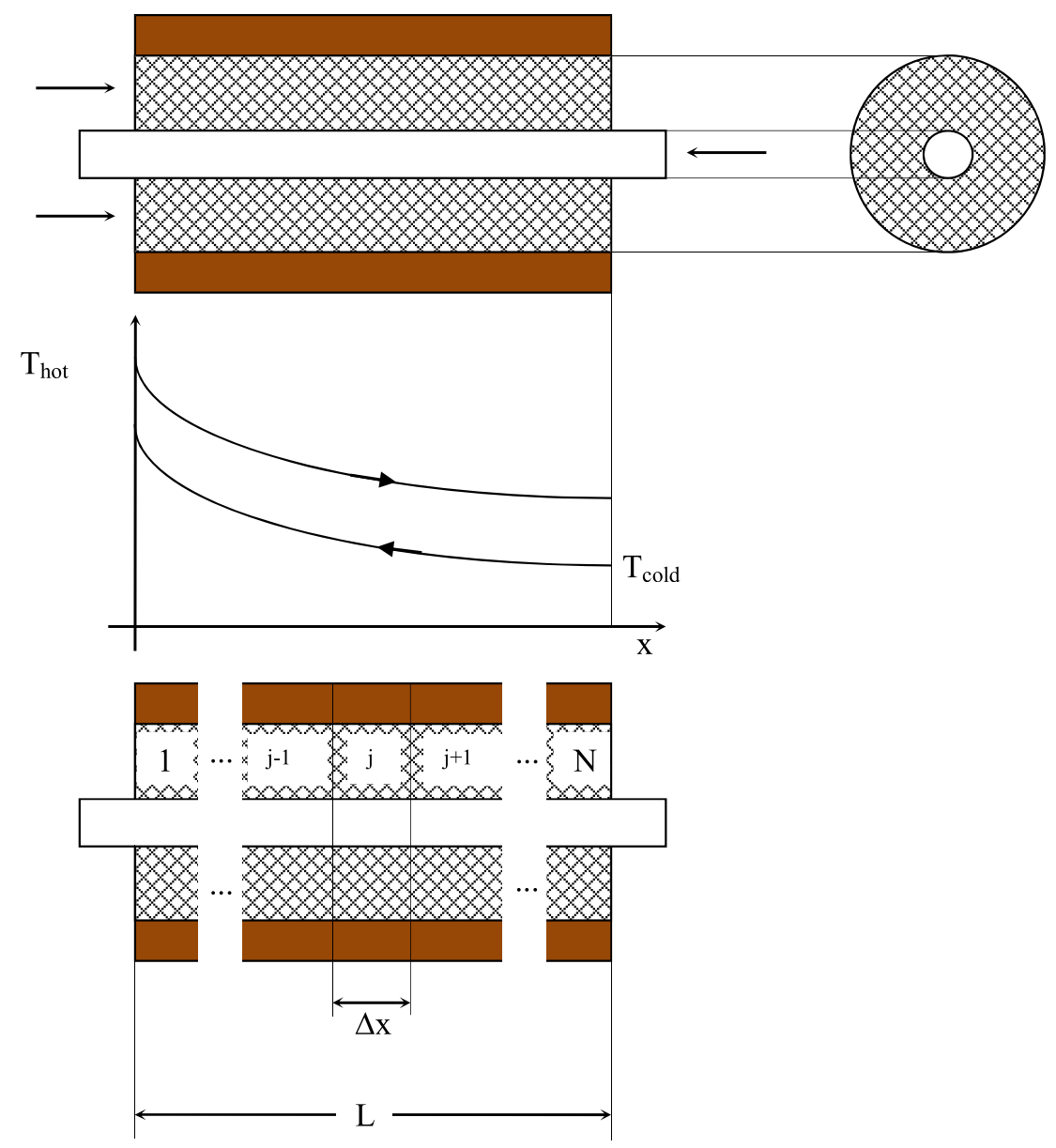

Figure 6. Schematic diagram of a and counterflow regenerative heat exchanger (top), expected temperature profiles of hot and cold streams (middle), and equipment division in volume elements (bottom). 


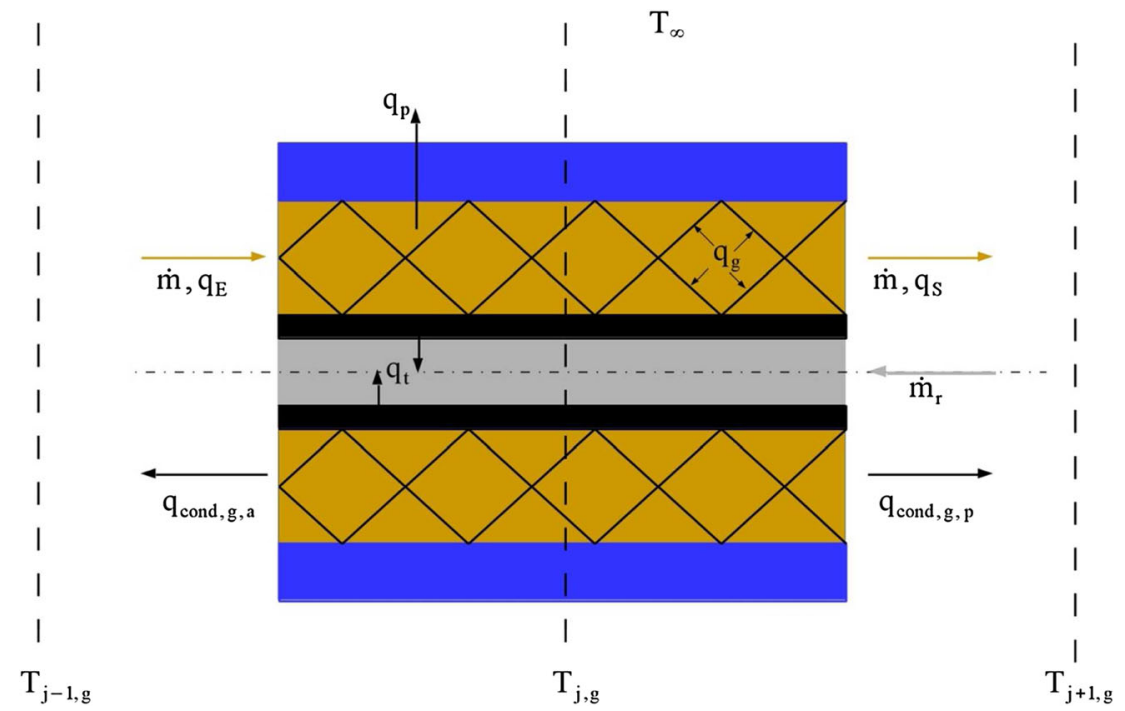

Figure 7. Details of a VE 'j' as defined in Figure 6 (bottom), showing mass and energy transfers between subsystems.

By applying the first law of thermodynamics to subsystem 1, as shown in Figure 7, the following equation is obtained:

$$
\mathrm{m}_{\mathrm{g}, \mathrm{j}} \mathrm{c}_{\mathrm{g}} \frac{\mathrm{dT}_{\mathrm{g}, \mathrm{j}}}{\mathrm{dt}}=\mathrm{q}_{\mathrm{g}}+\mathrm{q}_{\text {cond,g,a }}+\mathrm{q}_{\text {cond,g, } \mathrm{p}}+\mathrm{q}_{\mathrm{t}}
$$

where

$$
\begin{gathered}
\mathrm{q}_{\mathrm{g}}=\mathrm{h}_{\mathrm{g}}\left(\mathrm{A}_{\mathrm{gl}, \mathrm{j}}+\mathrm{A}_{\mathrm{t}, \mathrm{j}}\right)\left(\mathrm{T}_{\mathrm{j}}-\mathrm{T}_{\mathrm{g}, \mathrm{j}}\right) \\
\mathrm{q}_{\mathrm{t}}=\mathrm{h}_{\mathrm{t}} \mathrm{A}_{\mathrm{tl}, \mathrm{j}}\left(\mathrm{T}_{\mathrm{r}, \mathrm{j}}-\mathrm{T}_{\mathrm{g}, \mathrm{j}}\right) \\
\mathrm{q}_{\text {cond,g,a }}=-\mathrm{k}_{\mathrm{g}}\left(\mathrm{A}_{\mathrm{gs}}+\mathrm{A}_{\mathrm{gt}}\right) \frac{\mathrm{T}_{\mathrm{g}, \mathrm{j}}-\mathrm{T}_{\mathrm{g}, \mathrm{j}-1}}{\Delta \mathrm{x}} \\
\mathrm{q}_{\text {cond,g,p }}=-\mathrm{k}_{\mathrm{g}}\left(\mathrm{A}_{\mathrm{gs}}+\mathrm{A}_{\mathrm{gt}}\right) \frac{\mathrm{T}_{\mathrm{g}, \mathrm{j}}-\mathrm{T}_{\mathrm{g}, \mathrm{j}+1}}{\Delta \mathrm{x}}
\end{gathered}
$$

The porosity of the space, $\phi$, through which the hot fluid flows as shown in Figure 7 is an important parameter in the model because it affects the thermal response of the regenerator. It is possible to express the areas in Eqns. (11)-(14) as a function of porosity as follows:

$$
\begin{aligned}
\mathrm{A}_{\mathrm{tl}, \mathrm{j}} & =\pi \mathrm{d}_{\mathrm{t}} \Delta \mathrm{x} ; \mathrm{A}_{\mathrm{gl}, \mathrm{j}}=\frac{4(1-\phi) \mathrm{V}_{\mathrm{T}, \mathrm{j}}}{\mathrm{d}_{\mathrm{ar}}} ; \mathrm{A}_{\mathrm{gs}} \\
& =(1-\phi) \frac{\pi}{4}\left(\mathrm{D}^{2}-\mathrm{d}_{\mathrm{t}}^{2}\right) \text { and } \mathrm{A}_{\mathrm{gt}} \\
& =\frac{\pi}{4}\left(\mathrm{~d}_{\mathrm{t}}^{2}-\mathrm{d}_{\mathrm{t}, \text { int }}^{2}\right)
\end{aligned}
$$

where $\mathrm{V}_{\mathrm{T}, \mathrm{j}}=\pi / 4\left(\mathrm{D}^{2}-\mathrm{d}_{\mathrm{t}}^{2}\right) \Delta \mathrm{x}$.

The total mass of $\mathrm{VE} j$ is expressed as a function of total grid and tube volumes in VE $\mathrm{j}$, as follows:

$$
\mathrm{m}_{\mathrm{g}, \mathrm{j}}=\rho_{\mathrm{g}} \mathrm{V}_{\mathrm{g}, \mathrm{j}}
$$

where $\mathrm{V}_{\mathrm{g}, \mathrm{j}}=\left(\mathrm{A}_{\mathrm{gs}}+\mathrm{A}_{\mathrm{gt}}\right) \Delta \mathrm{x}$.

The boundary conditions are defined as

First volume element (cell) : $\mathrm{q}_{\text {cond,g,a }}=\mathrm{q}_{\text {cond,p,a }}=0$

Last volume element (cell) : $\mathrm{q}_{\text {cond,g,p }}=\mathrm{q}_{\text {cond,p,p }}=0$

Equations (17) and (18) assume that the heat transfer through the ends of the regenerator is negligible with respect to the heat leakage through the external side wall.

Subsytem 2. hot fluid flow (yellow in Figure 7)

By applying the first law of thermodynamics to subsystem 2 and adopting variables without subscript for this particular subsystem, which refers to hot fluid, the following equation is obtained:

$$
\mathrm{m}_{\mathrm{j}} \mathrm{c}_{\mathrm{v}} \frac{\mathrm{dT}_{\mathrm{j}}}{\mathrm{dt}}=\mathrm{q}_{\mathrm{E}}-\mathrm{q}_{\mathrm{s}}-\mathrm{q}_{\mathrm{g}}+\mathrm{q}_{\mathrm{p}}
$$

in which

$$
\begin{gathered}
\mathrm{q}_{\mathrm{p}}=(\mathrm{UA})_{\mathrm{p}, \mathrm{j}}\left(\mathrm{T}_{\infty}-\mathrm{T}_{\mathrm{j}}\right) \\
\mathrm{q}_{\mathrm{E}}-\mathrm{q}_{\mathrm{S}}=\dot{\mathrm{m}} \mathrm{c}_{\mathrm{p}}\left(\mathrm{T}_{\mathrm{j}-1}-\mathrm{T}_{\mathrm{j}}\right)
\end{gathered}
$$

with

$$
\begin{aligned}
& \mathrm{A}_{\mathrm{p}, \mathrm{j}}=\pi \mathrm{D} \Delta \mathrm{x}, \mathrm{A}_{\mathrm{pl}, \mathrm{j}}=\pi \mathrm{D}_{\mathrm{p}} \Delta \mathrm{x} \text { and } \mathrm{m}_{\mathrm{j}}=\rho \phi \mathrm{V}_{\mathrm{T}, \mathrm{j}} \\
& (\mathrm{UA})_{\mathrm{p}, \mathrm{j}}=\left\{\frac{1}{\mathrm{~h}_{\mathrm{g}} \mathrm{A}_{\mathrm{p}, \mathrm{j}}}+\frac{\ln \left(\mathrm{D}_{\mathrm{p}} / \mathrm{D}\right)}{2 \pi \mathrm{k}_{\mathrm{p}} \mathrm{L}}+\frac{1}{\mathrm{~h}_{\mathrm{ext}} \mathrm{A}_{\mathrm{pl}, \mathrm{j}}}\right\}^{-1}
\end{aligned}
$$


The boundary conditions are

$$
\mathrm{T}_{0}=\mathrm{T}_{\mathrm{E}}(\text { known parameter }) \text { and } \frac{\partial \mathrm{T}_{\mathrm{n}}}{\partial \mathrm{x}}=0
$$

Subsytem 3. internal fluid flow (gray in Figure 7)

By applying the first law of thermodynamics to subsystem 3, the following equation is obtained:

$$
\mathrm{m}_{\mathrm{r}, \mathrm{j}} c_{\mathrm{vr}} \frac{\mathrm{dT}_{\mathrm{r}, \mathrm{j}}}{\mathrm{dt}}=-\mathrm{q}_{\mathrm{t}}+\dot{\mathrm{m}}_{\mathrm{r}} \mathrm{c}_{\mathrm{pr}}\left(\mathrm{T}_{\mathrm{r}, \mathrm{j}+1}-\mathrm{T}_{\mathrm{r}, \mathrm{j}}\right)
$$

in which $\mathrm{m}_{\mathrm{r}, \mathrm{j}}=\rho_{\mathrm{r}}\left(\pi \mathrm{d}_{\mathrm{t}, \text { int }}^{2} / 4\right) \Delta \mathrm{x}$.

The boundary conditions are

$$
\mathrm{T}_{\mathrm{r}, \mathrm{n}}=\mathrm{T}_{\mathrm{r}, \mathrm{E}}\left(\text { known parameter) and } \frac{\partial \mathrm{T}_{\mathrm{r}, 0}}{\partial \mathrm{x}}=0\right.
$$

In this study, convective heat transfer coefficients, $\mathrm{h}_{\mathrm{g}}$, $h_{t}$, and $h_{\text {ext }}$ are considered as constants, but it is possible to consider the dependence on the Reynolds ( $\mathrm{Re})$ and Prandtl (Pr) numbers using empirical correlations [25].

Lastly, with the known temperature distribution of the equipment, it is possible to assess the heat exchanger performance, for example, from the effectiveness, as follows:

$$
\varepsilon=\frac{\dot{\mathrm{Q}}_{\text {real }}}{\dot{\mathrm{Q}}_{\max }}=\frac{\dot{\mathrm{m}} \mathrm{c}_{\mathrm{pr}}\left(\mathrm{T}_{\mathrm{r}, \mathrm{E}}-\mathrm{T}_{\mathrm{r}, \mathrm{S}}\right)}{\dot{\mathrm{m}} \mathrm{c}_{\mathrm{pr}}\left(\mathrm{T}_{\mathrm{r}, \mathrm{E}}-\mathrm{T}_{\mathrm{E}}\right)} \leq 1
$$

$\varepsilon=\frac{\mathrm{T}_{\mathrm{r}, \mathrm{E}}-\mathrm{T}_{\mathrm{r}, \mathrm{S}}}{\mathrm{T}_{\mathrm{r}, \mathrm{E}}-\mathrm{T}_{\mathrm{E}}}=\mathrm{f}($ design and operating parameters $)$

\subsection{Thermal management in power electronics and notional all-electric ships}

For the systems under analysis in this VEM application example, that is, cabinets for power electronics and an all-electric ship, the distinction of subsystems in each VE is not of interest to characterize the energy engineering system functionality and performance. For this reason, the model uses the first VEM alternative to treat mixed elements, that is, as a mixture of homogeneous entities (substances) in a single phase, calculating uniform properties for the VE. Hence, in general, the mathematical model developed in this section, could be applied to the thermal management of any similar system.

In thermal management, the main problem consists of calculating the temperature and relative humidity fields inside the system under consideration. In this manner, it is possible to anticipate whether the electronic devices and their operating point lie within the acceptable environmental conditions. In case of the environmental conditions imposed for human use, thermal management helps to verify adequate conditions for thermal comfort.
Figure 8 shows a schematic diagram of a PEBB. Such equipment form a power converter, and each one of the components generates heat at a known rate. The problem consists of calculating the temperature and relative humidity fields inside the cabinet. The components of interest include heat sink/thyristors, inductor, alternating current and direct current fuses, and capacitors.

The next study considers a US Navy notional allelectric ship, destroyer DDG-51, operating in mediumvoltage direct current. Figure 9 shows a computer-aided design image of a destroyer-type DDG-51. The problem consists of calculating the temperature and relative humidity fields inside the ship with respect to time and external ambient conditions.

The application of VEM starts by identifying the computational domain, followed by the discretization of the domain in VEs representing all components of interest in the system. In both systems selected as examples, there are VEs of fluid, solid, and mixture (solid + fluid) types.

A general mathematical model for thermal management is derived from Eqn. (1), using the second line in Table II, that is, an equation for conservation of energy, which results in Eqns. (7) and (8) that determine the temperature field in the computational domain. The model uses a velocity field, which is approximated by satisfying the mass conservation through Eqn. (6) for the entire system.

This model was developed in previous works published by the authors [17,18]. The VEM-based thermal management tool—vemESRDC — was developed as a part of the Electric Ship Research and Development Consortium led by the US Office of Naval Research. The tool is capable of obtaining quick responses during the early stages of ship design.

The relative humidity in each VE with air, $\varphi_{i}$, can be calculated from the temperature field, assuming a known initial relative humidity field $\varphi_{\mathrm{i} 0}$. The initial vapor pressure in VE $\mathrm{i}$ is calculated as

$$
\mathrm{p}_{\mathrm{v}, \mathrm{i}}=\varphi_{\mathrm{i} 0} \cdot \mathrm{p}_{\mathrm{vs}}\left(\mathrm{T}_{\mathrm{i} 0}\right)
$$

where $p_{v s}\left(T_{i 0}\right)$ is the saturation pressure of water at temperature $\mathrm{T}_{\mathrm{i} 0}$.

It is assumed that the absolute humidity in each VE remains approximately constant during the entire simulation. Hence, the relative humidity at each element that contains air is computed from

$$
\mathrm{p}_{\mathrm{v}, \mathrm{i}}=\varphi_{\mathrm{i} 0} \cdot \mathrm{p}_{\mathrm{vs}}\left(\mathrm{T}_{\mathrm{i} 0}\right)
$$

where $p_{v s}\left(T_{i}\right)$ is the saturation pressure of water at the VE temperature, $\mathrm{T}_{\mathrm{i}}$. When the element contains solids, fluids, or a mixture of both, the relative humidity is set to zero, that is, $\varphi_{\mathrm{i}}=0$.

\subsubsection{Heat transfer rate across element faces}

Empirical correlations are used to calculate the heat transfer rates across the faces of each VE. There are two 


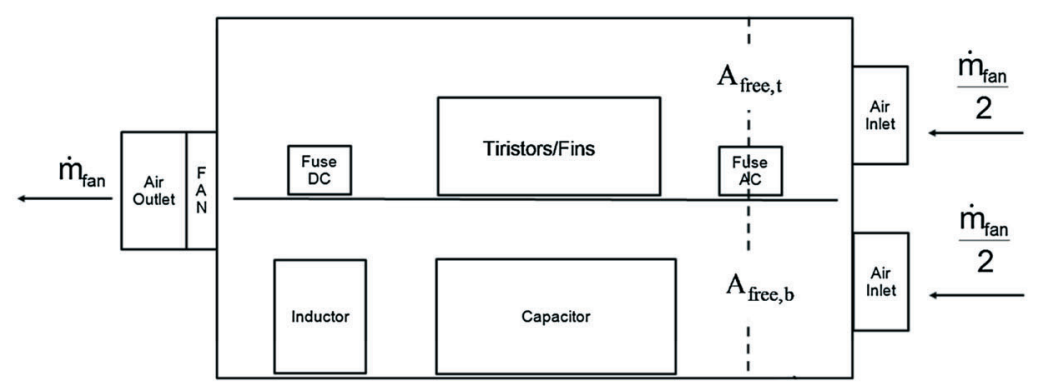

(a)

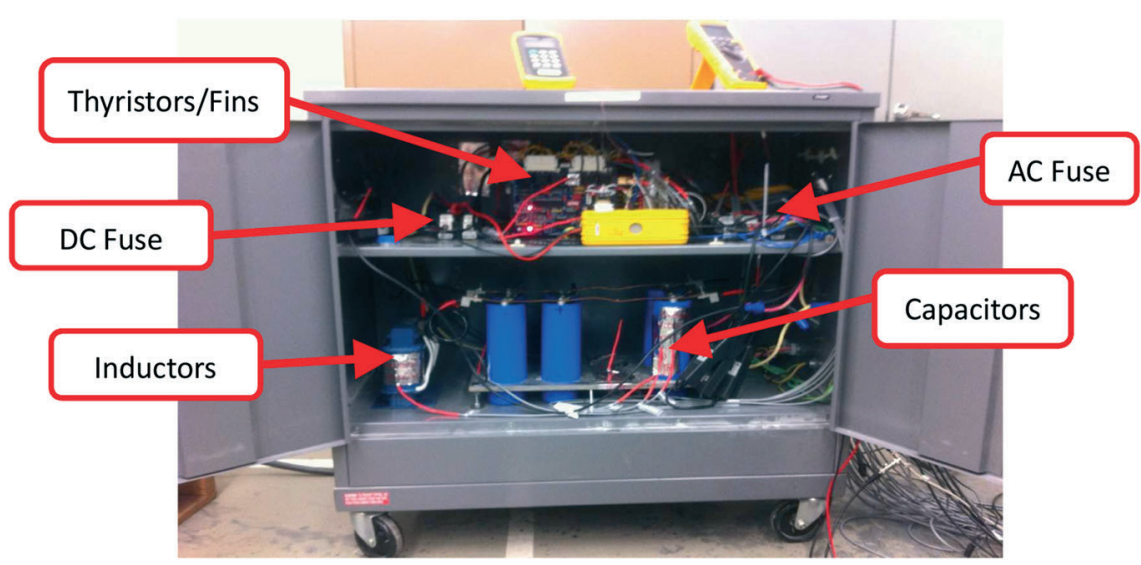

(b)

Figure 8. (a) Schematic diagram and (b) photo of internal component distribution in a cabinet for power electronic devices.

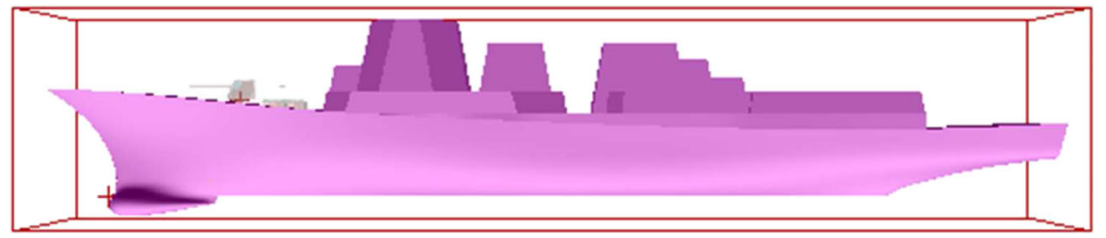

Figure 9. Computer-aided design image of a USA destroyer DDG-51 operating with baseline architecture of medium-voltage direct current.

possibilities for each face: the face is in contact either with the exterior or with another element.

\subsubsection{Element face in contact with the exte-}

rior. The element can contain solid equipment or fluid, and one or more faces may be in contact with the exterior. Heat transfer rates by conduction, convection, and radiation are taken into account as appropriate. Heat transfer by radiation across each element face is calculated by

$$
\begin{aligned}
\dot{\mathrm{Q}}_{\mathrm{rad}, \mathrm{i}, \mathrm{j}} & =\mathrm{A}_{\mathrm{i}, \mathrm{j}}\left\{\alpha_{\mathrm{j}} \mathrm{I}-\varepsilon_{\mathrm{j}} \sigma\left(\mathrm{T}_{\mathrm{i}, \mathrm{j}}^{4}-\mathrm{T}_{\mathrm{ext}}^{4}\right)\right\}, \quad \mathrm{j} \\
& =\mathrm{e}, \mathrm{w}, \mathrm{n}, \mathrm{s}, \mathrm{t}, \mathrm{b}
\end{aligned}
$$

where the first term in the curly brackets represents the portion of the average sun irradiation absorbed by the face, when there is sun incidence; $\mathrm{T}_{\mathrm{ext}}=\mathrm{T}_{\infty}$ (exterior air temperature) or $\mathrm{T}_{\mathrm{ext}}=\mathrm{T}_{\mathrm{sw}}$ (other external surrounding fluid temperature); $\alpha$ and $\varepsilon$ are the absorptivity and emissivity of the element face, respectively, $\sigma$ is the Stefan-Boltzmann constant, and $\mathrm{A}_{\mathrm{i}, \mathrm{j}}$ is the element face area [26]. It is also assumed that $I=0$ when the surface is in contact with other fluid or elements that block the passage of the sun radiation.

The overall heat transfer rate (radiation, conduction, and convection) across each element face is therefore computed as follows:

$$
\begin{aligned}
\dot{\mathrm{Q}}_{\mathrm{i}, \mathrm{j}} & =\dot{\mathrm{Q}}_{\mathrm{rad}, \mathrm{i}, \mathrm{j}}+\mathrm{U}_{\mathrm{i}, \mathrm{j}} \mathrm{A}_{\mathrm{i}, \mathrm{j}}\left(\mathrm{T}_{\mathrm{ext}}-\mathrm{T}\right)_{\mathrm{i}}, \mathrm{j} \\
& =\mathrm{e}, \mathrm{w}, \mathrm{n}, \mathrm{s}, \mathrm{t}, \mathrm{b}
\end{aligned}
$$

where the overall heat transfer coefficient, $U_{i, j}$, is given by 


$$
\begin{gathered}
U_{i, j}=\frac{1}{R_{i, j}} \\
R_{i, j}=\frac{l_{i, j} / 2}{k_{i}}+\frac{t_{w}}{k_{w}}+\frac{1}{h_{e x t}}(\text { solid element })
\end{gathered}
$$

or

$$
\mathrm{R}_{\mathrm{l}, \mathrm{i}}=\frac{1}{\mathrm{~h}_{\mathrm{int}}}+\frac{\mathrm{t}_{\mathrm{w}}}{\mathrm{k}_{\mathrm{w}}}+\frac{1}{\mathrm{~h}_{\mathrm{ext}}} \text { (fluid element) }
$$

where $\mathrm{l}_{\mathrm{i}, \mathrm{j}}$ is either the width or length of the element, $\mathrm{k}_{\mathrm{i}}$ the cell thermal conductivity, $\mathrm{t}_{\mathrm{w}}$ and $\mathrm{k}_{\mathrm{w}}$ the wall thickness and thermal conductivity, respectively, and $h_{\text {int }}$ and $h_{\text {ext }}$ the internal and external convective heat transfer coefficients, respectively.

The heat transfer coefficient $\mathrm{h}$ is given by

(a) Natural convection [27]:

$$
\mathrm{h}=\frac{\mathrm{k}_{\mathrm{f}}}{\mathrm{H}}\left\{0.825+\frac{0.387 \cdot \mathrm{Ra}_{\mathrm{H}}^{1 / 6}}{\left[1+(0.492 / \mathrm{Pr})^{9 / 16}\right]^{8 / 27}}\right\}^{2}
$$

where $\mathrm{k}_{\mathrm{f}}$ is the fluid thermal conductivity, Pr the Prandtl number of the fluid, $\mathrm{Ra}_{\mathrm{H}}=\left(\mathrm{g} \beta / \alpha_{\mathrm{T}} v\right) \mathrm{H}^{3} \mid \mathrm{T}_{\text {neigh,i }}-\mathrm{T}_{\mathrm{i}} \mathrm{l}, \mathrm{g}$ the gravity acceleration, $\beta$ the volumetric expansion coefficient of the fluid, $\alpha_{\mathrm{T}}$ the thermal diffusivity of the fluid, and $v$ the kinematic viscosity of the fluid; $\mathrm{T}_{\text {neigh, } \mathrm{i}}$ is the temperature of the neighboring VE or the exterior temperature, and $\mathrm{H}$ the total swept height of the solid under analysis.

Equation (36) is valid for all ranges of Rayleigh number -laminar, transitional, and turbulent-with fluid properties evaluated at the film temperature, that is, $\mathrm{T}_{\text {film }}=$ $\left(\mathrm{T}_{\text {neigh, }, \mathrm{i}}+\mathrm{T}_{\mathrm{i}}\right) / 2$.

Forced convection [28,29]:

$$
\mathrm{h}=\frac{\mathrm{k}_{\mathrm{f}}}{\mathrm{L}}\left(0.064 \operatorname{Pr}^{1 / 3} \operatorname{Re}_{\mathrm{L}}^{1 / 2}\right), \text { for } \operatorname{Re}_{\mathrm{L}}<5 \times 10^{5}
$$

or

$\mathrm{h}=\frac{\mathrm{k}_{\mathrm{f}}}{\mathrm{L}}\left\{0.037 \operatorname{Pr}^{1 / 3}\left(\operatorname{Re}_{\mathrm{L}}^{4 / 5}-23,550\right)\right\}$, for $\operatorname{Re}_{\mathrm{L}}>5 \times 10^{5}$

where $\operatorname{Re}_{\mathrm{L}}=\mathrm{v}_{\mathrm{f}} \mathrm{L} / v, \mathrm{v}_{\mathrm{f}}$ is the fluid velocity, and $\mathrm{L}$ is the length of the solid under analysis.

3.2.1.2. Lateral face in contact with other volume element. For the examples under analysis, it is assumed that there is no flow across a fluid/fluid boundary in the horizontal direction when the flow is ruled by natural convection; that is, flow is only in the vertical direction. In forced convection, the model admits the possibility of cooling through a cross flow, that is, in the direction the forced flow occurs, through the estimate of an approximate velocity field, as discussed previously in the text. Such assumptions greatly simplify the defining equations and thus speed up the calculations.

If the interface is fluid/fluid or solid/solid, under natural convection, only conduction takes place between adjacent elements, owing to the no-horizontal-flow assumption. The other possibility is a fluid/solid equipment interaction between the two elements, in which case heat transfer across the element face is ruled by convection.

For fluid/fluid contact, without flow in the horizontal direction, in other words, across the lateral faces, the heat transfer rate is given by

$$
\dot{\mathrm{Q}}_{\mathrm{l}, \mathrm{i}}=-\mathrm{U}_{1, \mathrm{i}} \mathrm{A}_{1, \mathrm{i}}\left(\mathrm{T}_{\mathrm{i}}-\mathrm{T}_{\mathrm{a}}\right), \mathrm{l}=\mathrm{e}, \mathrm{w}, \mathrm{n}, \mathrm{s}
$$

where a indicates the adjacent element and

$$
\mathrm{U}_{\mathrm{l}, \mathrm{i}}=\frac{\mathrm{k}_{\mathrm{f}}}{\left(1_{\mathrm{m}, \mathrm{i}}+1_{\mathrm{m}, \mathrm{a}}\right) / 2}
$$

where $1_{\mathrm{m}, \mathrm{i}}$ and $1_{\mathrm{m}, \mathrm{a}}$ are either the cell length or width, according to the index $\mathrm{m}=\mathrm{x}$ or $\mathrm{y}$, if the $\mathrm{i}$-th or a-th cell side face is east/west or north/south, respectively. For solid/ solid contact, the heat transfer rate is obtained with Eqn. (39), in which

$$
\mathrm{U}_{1, \mathrm{i}}=\frac{1}{\frac{l_{\mathrm{m}, \mathrm{i}} / 2}{\mathrm{k}_{\mathrm{i}}}+\frac{l_{\mathrm{m}, \mathrm{a}} / 2}{\mathrm{k}_{\mathrm{a}}}}
$$

When fluid/solid contact exists, the heat transfer by convection takes place, and Eqn. (39) is used with the overall heat transfer coefficient $\mathrm{U}_{1, \mathrm{i}}$ given by

$$
\mathrm{U}_{\mathrm{l}, i}=\mathrm{C}_{\mathrm{a}} \frac{1}{\frac{1}{\mathrm{~h}_{\mathrm{l}}}+\frac{\mathrm{l}_{\mathrm{m}, \mathrm{c}} / 2}{\mathrm{k}_{\mathrm{c}}}}
$$

where the index $c$ is the element number. $C_{a}=S_{\text {real }} / S_{\text {mesh }}$ is the correction factor for the convective surface area, where $\mathrm{S}_{\text {real }}$ is the true convective surface area of the solid component and $\mathrm{S}_{\text {mesh }}$ is the surface of area of the component represented in the mesh. In this way, the factor $C_{a}$ allows the simulated convective surface to have the same surface area as the actual component. This is especially important in the case of finned components, in which the representation in the mesh can differ by more than $100 \%$ to that of the actual equipment.

3.2.1.3. Face type top/bottom in contact with other element. Three types of interaction in VEs must be taken into account: (i) fluid/fluid; (ii) fluid/solid; and (ii) solid/solid.

\section{(a) Fluid/fluid}

Both elements contain fluid and the heat flux is given by

$$
\dot{\mathrm{Q}}_{\mathrm{l}, \mathrm{i}}=\dot{\mathrm{m}}_{\mathrm{l}, \mathrm{i}} \mathrm{c}_{\mathrm{p}, \mathrm{f}}\left(\mathrm{T}_{\mathrm{a}}-\mathrm{T}_{\mathrm{i}}\right), \mathrm{l}=\mathrm{t}, \mathrm{b}
$$

where $\dot{\mathrm{m}}_{1, \mathrm{i}}=\rho_{\mathrm{f}} \mathrm{v}_{\mathrm{i}}\left(\mathrm{A}_{\mathrm{l}, \mathrm{i}} / 2\right)$. 
For natural convection, an estimate of the fluid velocity crossing the element surface is given by $v_{i}=\alpha_{T}\left[\left(g \beta / \alpha_{T} v\right) \mid T_{a}\right.$ $\left.\mathrm{T}_{\mathrm{i}} \mid \mathrm{H}\right]^{1 / 2}$, which is a representative scale for natural convection $[28,29]$. It is assumed that half of the top or bottom face of an element is crossed by a flow in the vertical upward direction, and the other half in the opposite direction.

In case of forced convection, Eqn. (43) is used with an approximate velocity field $\mathrm{v}_{\mathrm{f}}$ (e.g., fan or air conditioning system) crossing the domain in the horizontal direction; then it will be necessary to compare $v_{i}$ and $v_{f}$. If the velocity due to natural convection is greater than the approximate velocity field, then the velocity due to natural convection is used; otherwise, the approximate velocity field is appropriate.

\section{(b) Fluid/solid}

Heat flux crossing the top or bottom face follows Eqn. (39), with index $1=\mathrm{t}, \mathrm{b} . \mathrm{U}_{1, \mathrm{i}}$ is computed with Eqn. (42), and $l_{m, c}$ is substituted by $l_{z, c}$.

\section{(c) Solid/solid}

When both elements contain solid components, the heat flux is also calculated following Eqn. (39) with $U_{1, i}$ given by Eqn. (41), where $1=\mathrm{t}$, b. Lengths $1_{\mathrm{m}, \mathrm{i}}$ and $1_{\mathrm{m}, \mathrm{a}}$ are substituted by $\mathrm{l}_{\mathrm{z}, \mathrm{i}}$ and $\mathrm{l}_{\mathrm{z}, \mathrm{a}}$, respectively.

\subsubsection{Heat transfer rates collected/rejected by cooling fluids}

For the two systems under analysis, three VE types are classified in subtypes in order to improve the model and to account for different components in the subsystem and their cooling strategies. Seven subtypes of VE are defined in accordance with the content: (0) only air; (1) pure solid; (2) compact heat exchanger; (3) chilled fluid units; (4) internal fluid (closed-loop) cooled systems; (5) external fluid (open-loop) cooled systems; and (6) fluid element cooled by cross flow (e.g., external air flow induced by fans).

The system is divided into zones, where each zone is cooled separately, with combinations of, for example, air conditioning and external and internal closed water loop. The system may contain cross-connects between zones to increase redundancy. For ease of discussion, the text refers to the internal fluid from this point on as 'freshwater', recognizing that it could be fresh, de-ionized, or a waterantifreeze mix. Similarly, it refers to the external fluid as 'seawater'.

The freshwater flows in a closed loop, collecting heat from the heat-generating systems within the zone and then rejecting heat to the cold external fluid (seawater) stream via a heat exchanger, or a chilled fluid unit, or both; that is, there could be only the heat exchanger or the chilled fluid unit, or they could operate in series. For example, the use of a heat exchanger is not of interest when the available cold stream is at a higher temperature than the freshwater maximum temperature. Other cooling strategies such as systems cooled by air conditioning and directly by seawater may be used. The goal of this combined cooling strategy is that the zones and the entire integrated system temperature and relative humidity fields remain within acceptable and pre-established design limits.

To clarify the description for each element subtype and cooling strategies presented in the previous paragraphs, an all-electric ship is illustrated as an example. Figure 10 summarizes the distribution of components of the notional ship operating with medium-voltage direct current, their respective zones, and a proposal for a general cooling strategy, including seawater, freshwater, and air conditioning systems. The major loads are shown individually (e.g., gas turbine and pulsating load), while smaller loads are grouped together to simplify the modeling of loads cooled by auxiliary seawater (blue), freshwater (green), and air conditioning (red).

The calculation begins by determining the internal fluid temperature at the inlet of the heat exchanger in each integrated system zone. For that, a freshwater mixing section is placed before the heat exchanger inlet, in which the inputs are the mass flow rates that come from the output of each component cooled by freshwater and the output is the total freshwater mass flow rate. Hence, a steady-state energy balance (assuming negligible thermal inertia) in the mixer allows for the calculation of the temperature at the outlet of each zone, which is also the heat exchanger freshwater inlet temperature, as follows:

$$
\mathrm{T}_{\mathrm{fw}, \mathrm{in}}=\frac{\sum_{\mathrm{j}=1}^{\mathrm{n}_{\mathrm{eq}}} \dot{\mathrm{m}}_{\mathrm{fw}, \mathrm{j}} \mathrm{T}_{\mathrm{j}}}{\dot{\mathrm{m}}_{\mathrm{fw}}}
$$

where $\dot{\mathrm{m}}_{\mathrm{fw}, \mathrm{j}}$ is the freshwater mass flow rate coming from component $\mathrm{j}, \mathrm{T}_{\mathrm{j}}$ is the temperature of component $\mathrm{j}$ (assuming thermal equilibrium with the fluid temperature leaving the system), $\dot{\mathrm{m}}_{\mathrm{fw}}$ is the total freshwater mass flow rate in the zone, and $n_{\mathrm{eq}}$ is the total number of components cooled by freshwater in the zone. When $\dot{\mathrm{m}}_{\mathrm{fw}}=0$ (e.g., pump off) in a particular zone, Eqn. (44) cannot be not used.

The heat transfer rates collected/rejected by internal or external fluid (i.e., freshwater or seawater), $\dot{Q}_{\text {conv }, \mathrm{i}}=$ $\sum_{j=e, w, t, b, n, s} \dot{G}_{a d v, j, i}$ for Eqn. (2), are calculated for each element type as follows:

(i) Element type 2 (heat exchanger)

The effectiveness number of heat transfer units (NTU) method $[25,28]$ is used to estimate the heat exchanger effectiveness, which can be applied to any type of compact heat exchanger [25]. Assuming a counterflow compact heat exchanger, the effectiveness is given by 


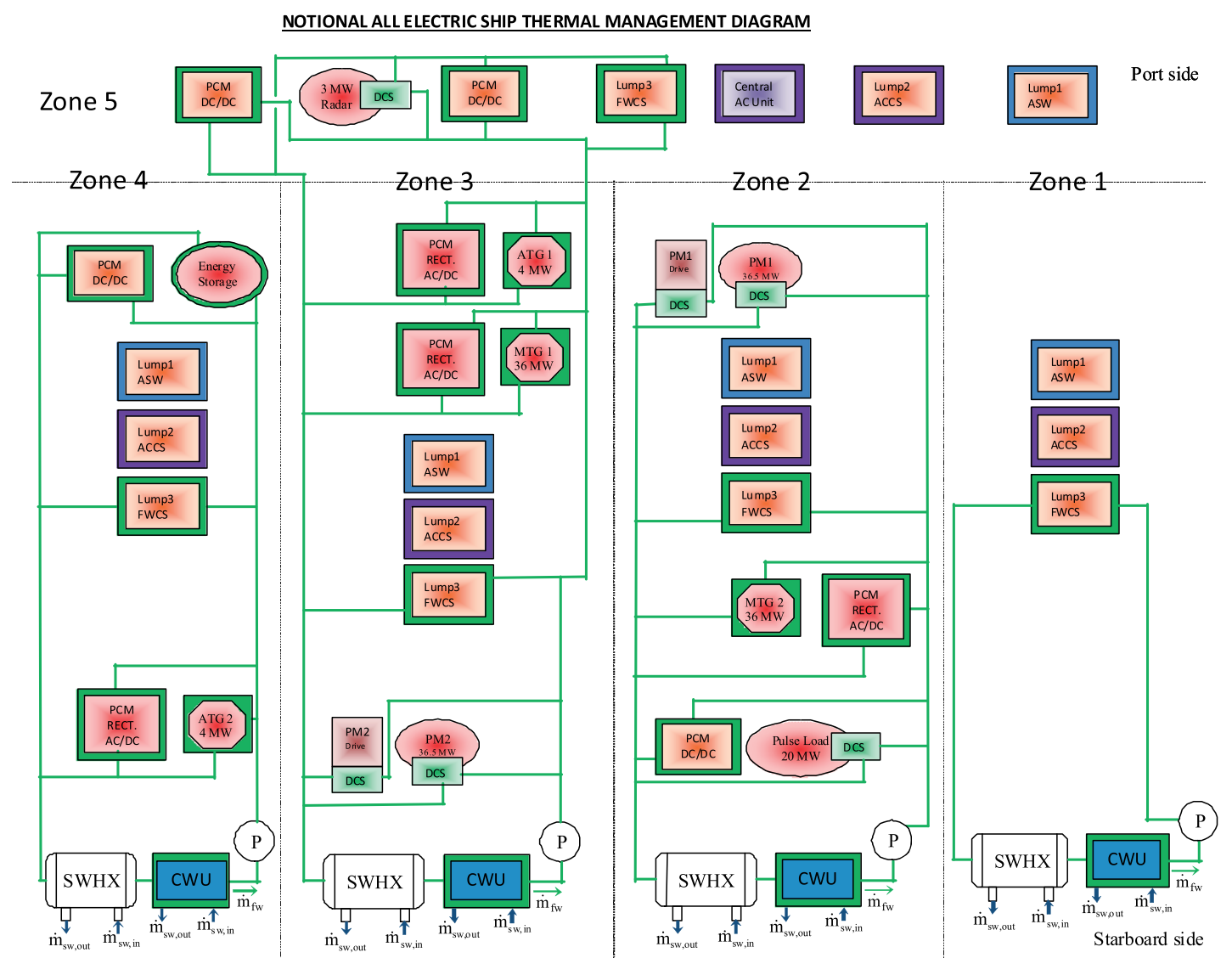

Figure 10. Schematic diagram of notional equipment and cooling circuits, where AC is the air conditioning, ACCS the air-conditioned cooled system, DC/DC the direct to direct current, AC/DC the alternating to direct current, ASW the auxiliary seawater cooled, ATG the auxiliary gas turbine, CWU the chilled water unit, DCS the dedicated cooling system, FWCS the freshwater-cooled system, MTG the main gas turbine generator, $\mathrm{P}$ the pump, PCM the power conversion module, PM the propulsion motor, RECT the rectifier, and SWHX the seawater heat exchanger [34].

$\varepsilon_{\mathrm{hx}}=\frac{1-\exp \left\{-\mathrm{NTU}\left(1-\mathrm{C}_{\min } / \mathrm{C}_{\max }\right)\right\}}{1-\left(1-\mathrm{C}_{\min } / \mathrm{C}_{\max }\right) \exp \left\{-\mathrm{NTU}\left(1-\mathrm{C}_{\min } / \mathrm{C}_{\max }\right)\right\}}$

where $\mathrm{NTU}=(\mathrm{UA})_{\mathrm{hx}} / \mathrm{C}_{\text {min }}$; $\mathrm{U}$ and $\mathrm{A}$ are overall heat transfer coefficient and heat transfer area, respectively; the subscript ' $h x$ ' refers to the heat exchanger; $C_{\min }=$ $(\dot{m c})_{i}$ is the smaller heat capacity among the two flows ( $\mathrm{i}=$ internal or external flow); and $\mathrm{C}_{\max }$ is the larger heat capacity between the two.

With the definition of the effectiveness-NTU method and Eqn. (45), the temperature at the outlet of the seawater heat exchanger is calculated as

$$
\mathrm{T}_{\mathrm{sw}, \text { out }}=\frac{\varepsilon_{\mathrm{hx}} \dot{\mathrm{m}}_{\mathrm{fw}} \mathrm{c}_{\mathrm{fw}}\left(\mathrm{T}_{\mathrm{fw}, \text { in }}-\mathrm{T}_{\mathrm{sw}, \text { in }}\right)}{\dot{\mathrm{m}}_{\mathrm{sw}} \mathrm{c}_{\mathrm{sw}}}+\mathrm{T}_{\mathrm{sw}, \text { in }}
$$

where $\dot{\mathrm{m}}$ and $\mathrm{c}$ are the mass flow rate and specific heat, respectively, $\mathrm{T}$ is the temperature, the subscripts $\mathrm{fw}, \mathrm{sw}$, in, and out refer to freshwater, seawater, inlet, and outlet, respectively. When $\dot{\mathrm{m}}_{\mathrm{sw}}=0$ (the pump is off) in a particular zone, Eqns. (45) and (46) are not used and assumes no flow, which leads to $\dot{\mathrm{Q}}_{\text {conv }, \mathrm{i}}=0$.

Therefore, the heat transfer rate between the water flows in element type 2 is calculated as follows:

$$
\begin{aligned}
\dot{\mathrm{Q}}_{\mathrm{conv}, \mathrm{i}}= & \dot{\mathrm{m}}_{\mathrm{fw}} \mathrm{c}_{\mathrm{fw}}\left(\mathrm{T}_{\mathrm{fw}, \text { in }}-\mathrm{T}_{\mathrm{i}}\right) \\
& +\dot{\mathrm{m}}_{\mathrm{sw}} \mathrm{c}_{\mathrm{sw}}\left(\mathrm{T}_{\mathrm{sw}, \text { in }}-\mathrm{T}_{\mathrm{sw}, \text { out }}\right)
\end{aligned}
$$

where the subscript $\mathrm{i}$ refers to the element type 2 under consideration and $T_{i}$ is the temperature of the element, which is assumed to be equal to the exit temperature of freshwater, according to the assumption of uniform thermodynamic properties within the control volume.

\section{(ii) Element type 3 (chilled water unit)}

The heat transfer rate through the freshwater flowing across element type 3 is calculated as follows:

$$
\dot{\mathrm{Q}}_{\mathrm{conv}, \mathrm{i}}=\dot{\mathrm{m}}_{\mathrm{fw}} \mathrm{c}_{\mathrm{fw}}\left(\mathrm{T}_{\mathrm{swhx}, \mathrm{fw}, \text { out }}-\mathrm{T}_{\mathrm{i}}\right)
$$


where the subscript i refers to element type 3 under consideration and $T_{\text {swhx,fw,out }}$ is the chilled water unit freshwater inlet temperature, which corresponds to the seawater heat exchanger freshwater outlet temperature shown in a particular zone in Figure 10.

In element type $3, \dot{\mathrm{Q}}_{\mathrm{gen}} \leq 0$, which is a design parameter corresponding to the nominal cooling rate of the selected chiller. The equal sign refers to a situation when the unit is off. In this unit, it is assumed that the heat is rejected to an external water flow (e.g., seawater) that extracts heat from the condenser.

(iii) Element type 4 (freshwater-cooled components)

The net heat transfer rate through the freshwater stream crossing any element type 4 in the zone is calculated as follows:

$$
\dot{\mathrm{Q}}_{\mathrm{conv}, \mathrm{i}}=\dot{\mathrm{m}}_{\mathrm{fw}} \mathrm{c}_{\mathrm{fw}}\left(\mathrm{T}_{\mathrm{cw}, \text { out }}-\mathrm{T}_{\mathrm{i}}\right)
$$

where subscript $\mathrm{i}$ refers to the element type 4 under analysis and $\mathrm{T}_{\mathrm{cw}, \text { out }}$ is the chilled water unit outlet temperature of a particular zone, as shown in Figure 10.

Some components could have dedicated cooling systems, which could be a refrigeration system or a secondary heat exchanger. In the case of a dedicated refrigeration system, heat is extracted from the load through the evaporator, but the heat that is rejected by the condenser inside the element is given by

$$
\dot{\mathrm{Q}}_{\mathrm{gen}}=\frac{1+\eta}{\eta} \dot{\mathrm{Q}}_{\mathrm{evap}, \mathrm{DCS}}
$$

where $\dot{\mathrm{Q}}_{\mathrm{evap}, \mathrm{DCS}}$ is a design parameter corresponding to the nominal refrigeration rate of the refrigeration unit that was selected to locally cool the load, which is meant to match the component heat generation rate, and $\eta$ is the nominal unit thermal efficiency (or the coefficient of performance).

In the case of a secondary heat exchanger, $\dot{Q}_{g e n}$ is assumed to be the component heat generation rate.

\section{(iv) Element type 5 (auxiliary seawater systems)}

The net heat transfer rate with the auxiliary water stream crossing any element type 5 is calculated as follows:

$$
\dot{\mathrm{Q}}_{\mathrm{conv}, \mathrm{i}}=\dot{\mathrm{m}}_{\mathrm{asw}} \mathrm{c}_{\mathrm{sw}}\left(\mathrm{T}_{\mathrm{sw}, \mathrm{in}}-\mathrm{T}_{\mathrm{i}}\right)
$$

where the subscript $\mathrm{i}$ refers to the element type 5 and $\mathrm{T}_{\mathrm{sw} \text {,in }}$ is the seawater inlet temperature.

Element type 6 (cross flow cooled fluid element)

In order to account for the fluid element that is cooled by cross flow with a cooling stream (e.g., external air flow induced by a fan), an additional element subtype is defined. The heat transfer rate by convection, $\dot{\mathrm{Q}}_{\text {conv }, \mathrm{i}}$, is calculated as follows:

$$
\dot{\mathrm{Q}}_{\mathrm{conv}, \mathrm{i}}=\dot{\mathrm{m}}_{\mathrm{i}} \mathrm{c}_{\mathrm{p}, \mathrm{f}}\left(\mathrm{T}_{\mathrm{in}}-\mathrm{T}_{\mathrm{i}}\right)
$$

where $\dot{\mathrm{m}}_{\mathrm{i}}=\rho_{\mathrm{f}} \mathrm{v}_{\mathrm{i}} \mathrm{A}_{\mathrm{i}}, \mathrm{c}_{\mathrm{p}, \mathrm{f}}$ is the specific heat at constant pressure for a gas (e.g., air) or simply specific heat for a cooling fluid, $\rho_{\mathrm{f}}$ is the refrigerant density, $v_{\mathrm{i}}$ is the velocity at which the refrigerant crosses the face of $\mathrm{VE} \mathrm{i}, \mathrm{A}_{\mathrm{i}}$ is the side $\mathrm{VE}$ face area that is crossed by the cooling flow, and $\mathrm{T}_{\text {in }}$ is the inlet fluid temperature for VE i. For the VE located in the wall (domain boundary) where the refrigerant inlet is located, $T_{\text {in }}$ is the inlet refrigerant temperature, that is, the external air temperature.

The velocity at which the refrigerant crosses the face of VE $\mathrm{i}$ is estimated by

$$
\mathrm{v}_{\mathrm{i}}=\frac{\dot{\mathrm{m}}_{\mathrm{fan}}}{\rho_{\mathrm{f}} \mathrm{A}_{\mathrm{free}}}
$$

In Eqn. (53), $\dot{m}_{\text {fan }}$ is a known parameter, based on fan specification or directly measured at the orifice where the fan is installed, and $\mathrm{A}_{\text {free }}$ is the total cross-sectional area of the geometry under consideration. Therefore, the refrigerant flows around the equipment within the system, and $v_{i}$ for each VE with air is estimated based on the fluid properties and cross section of VE i. Conservation of mass is satisfied by noting that the inlet refrigerant mass flow rate in the system is the same as the outlet flow rate.

\section{NUMERICAL METHOD}

In the first VEM application example (regenerative heat exchanger), Eqns. (10), (19), and (25) form a system of $3 n$ ODEs and $3 n$ unknowns to be integrated in time, to obtain $T_{j}(t), T_{g, j}(t)$, and $T_{r, j}(t)$, starting from the known initial conditions $\mathrm{T}_{\mathrm{j}, 0}, \mathrm{~T}_{\mathrm{g}, \mathrm{j}, 0}$, and $\mathrm{T}_{\mathrm{r}, \mathrm{j}, 0}$, for $1 \leq \mathrm{j} \leq \mathrm{n}$.

In the second VEM application example (PEBB and allelectric ship), the mathematical model produces a system of $n$ (total number of VEs) ODEs with time as an independent variable, along with initial conditions, for the unknown variable, $T_{i}$, that is, the temperature of each VE. Once the temperature of each element is known, relative humidity is directly calculated via post-processing.

In order to obtain the dynamic response, the system of equations is integrated in time using a fourth-order and fifth-order Runge-Kutta/Fehlberg method [30] with given initial conditions and an adaptive step to control the local truncation error (LTE) such that LTE $\leq 10^{-4}$. To determine the time required to reach steady state, $t_{\text {regime}}$, a condition is set in which the norm of the time derivative of the vector with all variables being integrated is less than a pre-established tolerance; that is, $\|\partial \mathrm{T} / \partial \mathrm{t}\| \leq 10^{-3}$ in this study. 
If the transient solution is of no interest, the system can be directly solved for the steady-state solution. The time derivative terms in the system ODEs are dropped, and a system of $\mathrm{N}$ nonlinear algebraic equations is obtained. In this case, the unknowns are the steady-state temperatures at the center of each VE. Then the resulting nonlinear system of algebraic equations is solved using a Newton-Raphson method, and the system is linearized with respect to unknown values in the cell center. These methods were programmed using FORTRAN language.

The convergence of the numerical results was verified by successive mesh refinements [31] and monitoring the variation in the Euclidean norm of the numerical solution for the entire domain. Similarly, the maximum norm (or infinite norm) can also be used to reduce the computational effort. The results of a less refined mesh (mesh 1) are compared with the results of a more refined mesh (mesh 2), and the refinements stop when the mesh refinement relative error, $\varepsilon_{\text {mesh,i }}$, criterion is satisfied. Then mesh 1 is selected as the converged mesh based on the following equation:

$$
\varepsilon_{\text {mesh }, \mathrm{i}}=\frac{\left|\left\|\operatorname{var}_{\mathrm{i}}\right\|_{\text {mesh1 }}-\left\|\operatorname{var}_{\mathrm{i}}\right\|_{\text {mesh2 } 2}\right|}{\left\|\operatorname{var}_{\mathrm{i}}\right\|_{\text {mesh1 }}} \leq 0.01
$$

where $v r_{i}$ represents each of the unknowns in the problem under analysis, that is, the calculated temperatures in this study.

\section{RESULTS AND DISCUSSION}

\subsection{Regenerative heat exchanger}

The initial conditions used in the simulations were $T_{j, 0}=$ $\mathrm{T}_{\mathrm{g}, \mathrm{j}, 0}=\mathrm{T}_{\mathrm{r}, \mathrm{j}, 0}=293.15 \mathrm{~K}$, for $1 \leq \mathrm{j} \leq \mathrm{n}$. The physical parameters used in this example to simulate the system shown in Figures 6 and 7 were $n=20$ for the converged mesh based on the criterion of Eqn. (54), $\mathrm{L}=1 \mathrm{~m}, \mathrm{~d}_{\mathrm{t}}=0.05$ $\mathrm{m}, \mathrm{d}_{\mathrm{t} \text {,int }}=0.046 \mathrm{~m}, \mathrm{D}=0.1 \mathrm{~m}, \mathrm{~d}_{\mathrm{ar}}=0.02 \mathrm{~m}, \mathrm{D}_{\mathrm{p}}=0.12 \mathrm{~m}$, $\rho=1.165 \mathrm{~kg} \mathrm{~m}^{-3}, \rho_{\mathrm{g}}=2707 \mathrm{~kg} \mathrm{~m}^{-3}, \rho_{\mathrm{r}}=1000 \mathrm{~kg} \mathrm{~m}^{-3}, \mathrm{c}_{\mathrm{g}}=$ $896 \mathrm{~J} \mathrm{~kg} \mathrm{~K}^{-1}, \dot{\mathrm{m}}=0.1 \mathrm{~kg} \mathrm{~s}^{-1}, \dot{\mathrm{m}}_{\mathrm{r}}=0.01 \mathrm{~kg} \mathrm{~s}^{-1}, \mathrm{c}_{\mathrm{p}}=1000$ $\mathrm{J} \mathrm{kg} \mathrm{K}^{-1}, \quad \mathrm{c}_{\mathrm{v}}=713 \mathrm{~J} \mathrm{~kg} \mathrm{~K}^{-1} ; \quad \mathrm{c}_{\mathrm{vr}}=\mathrm{c}_{\mathrm{pr}}=4180 \mathrm{~J} \mathrm{~kg} \mathrm{~K}^{-1}$ (fluid), $\mathrm{k}_{\mathrm{g}}=204 \mathrm{~W} \mathrm{~m}^{-1} \mathrm{~K}^{-1}, \mathrm{k}_{\mathrm{p}}=1 \mathrm{~W} \mathrm{~m}^{-1} \mathrm{~K}^{-1}, \mathrm{~h}_{\mathrm{g}}=\mathrm{h}_{\mathrm{t}}=$ $100 \mathrm{~W} \mathrm{~m}^{-2} \mathrm{~K}^{-1}, \mathrm{~h}_{\text {ext }}=5 \mathrm{~W} \mathrm{~m}^{-2} \mathrm{~K}^{-1}, \mathrm{~T}_{\infty}=298.15 \mathrm{~K}, \mathrm{~T}_{\mathrm{E}}=$ $373.15 \mathrm{~K}$, and $\mathrm{T}_{\mathrm{r}, \mathrm{E}}=293.15 \mathrm{~K}$.

Figure 11 illustrates the steady-state temperature variation along the stream (with respect to $\mathrm{x}$ ) in the counter-flow heat exchanger as a function of different porosities. In Figure 11a, with $\phi=0.95$, that is, low-mass grid in the hot space of Figure 7, the curves are far apart, and the internal fluid warms slightly because of poor thermal contact, characterizing a low effectiveness value calculated using Eqn. (28); that is, $\varepsilon=0.27$. Figure 11, panels b $(\phi=0.5 ; \varepsilon=0.956)$ and $\mathrm{c}(\phi=0.2 ; \varepsilon=0.965)$, shows that the effectiveness is greater when the porosity is low (more metal), as additional metal mass implies a larger heat transfer area, as is physically expected. The time required to reach steady state presented an inverse trend; that is, time increases as the metal mass increases (porosity reduces) because of increased thermal inertia, that is, Figure 11 , panels a $\left(\phi=0.95 ; t_{\text {regime }}=330 \mathrm{~s}\right), \mathrm{b}$ $\left(\phi=0.5 ; \mathrm{t}_{\text {regime }}=930 \mathrm{~s}\right)$, and $\mathrm{c}\left(\phi=0.2 ; \mathrm{t}_{\text {regime }}=1650 \mathrm{~s}\right)$. Such opposing trends must be balanced when designing a regenerative heat exchanger, depending on the specific application. As a practical application of the model, Figure $11 \mathrm{c}$ shows that the internal fluid was heated to about the same temperature and the effectiveness is practically the same when the heat exchanger length is reduced (e.g., $0.2 \mathrm{~m}$ ), resulting in material savings and also possible system size reduction.

In order to evaluate how porosity affects the effectiveness when the hot stream flow rate changes, a mass flow rate variation is adopted using a periodic function; that is, $\dot{\mathrm{m}}=\left(\dot{\mathrm{m}}_{\max } / 2\right) \cos (t / 60)+\left(\dot{\mathrm{m}}_{\max } / 2\right)$. In this study, the simulation ran until $t=1000 \mathrm{~s}$. The results for the first system are shown in Figure $12 \mathrm{a} \quad(\phi=0.95)$ and $\mathrm{b}$ $(\phi=0.5)$. When the porosity decreases, that is, more metal mass, the thermal inertia of the system increases, and the temperature curves become closer to each other, characterizing the expected regenerative system behavior, that is, to allow constant heat exchanger operation even when the hot stream flow rate varies. Furthermore, the results show that the thermal response of a regenerator becomes more robust as the porosity decreases.

\subsection{Thermal management in power electronics}

The PEBB shown in Figure 8 was numerically and experimentally studied by Dilay et al. [18]. Experimental measurements are used to validate the mathematical model previously presented, using two different sets of measured data obtained for the PEBB shown in Figure 8 for two different power inputs. The procedure consists of solving the IPPE to verify and adjust, if necessary, estimated equivalent densities, specific heats, heat transfer surfaces, or thermal conductivities of the components, adjusting the mathematical model using the first set of data with a specific power input, that is, $4.8 \mathrm{~kW}$. Next, the conditions corresponding to the other data set, that is, $11.12 \mathrm{~kW}$, are computationally simulated with the adjusted model to verify the agreement between numerical and experimental results in order to experimentally validate the mathematical model.

\subsubsection{PEBB model adjustment}

A computer code was written in FORTRAN based on the numerical method described in Section 3 to obtain the solution to the mathematical model presented in Section 2, that is, PEBB internal air and component temperatures. The input parameters are the PEBB geometric features, components' heat generation rate, and 


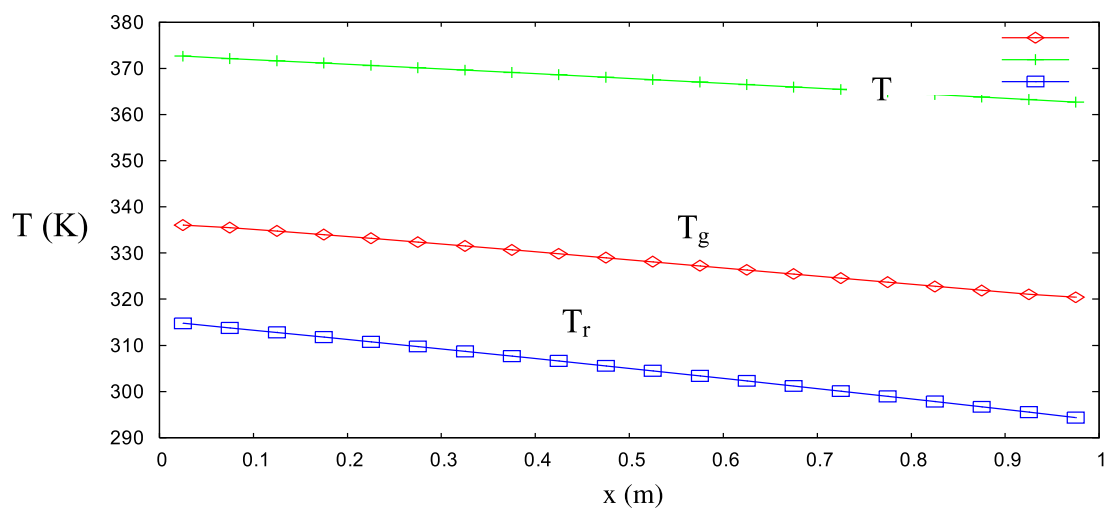

(a)

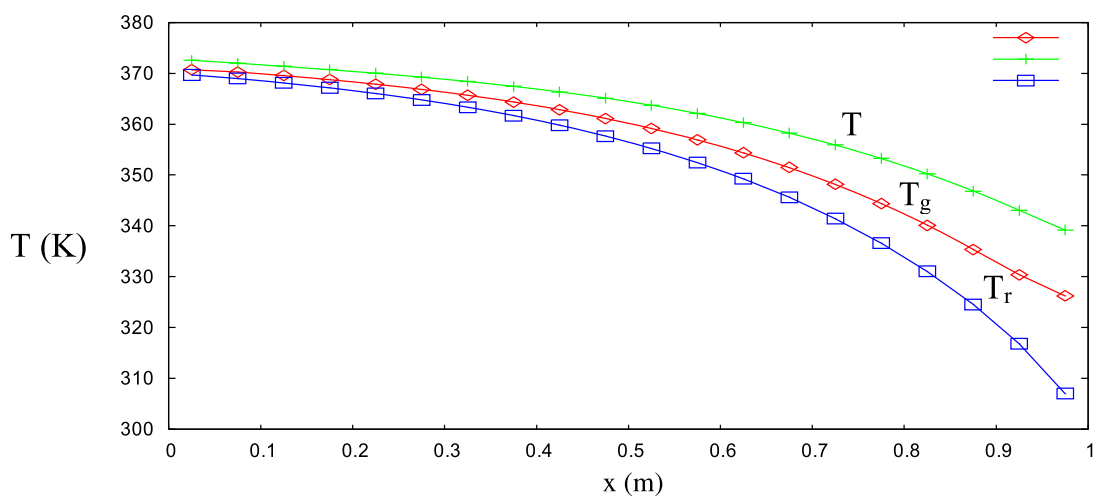

(b)

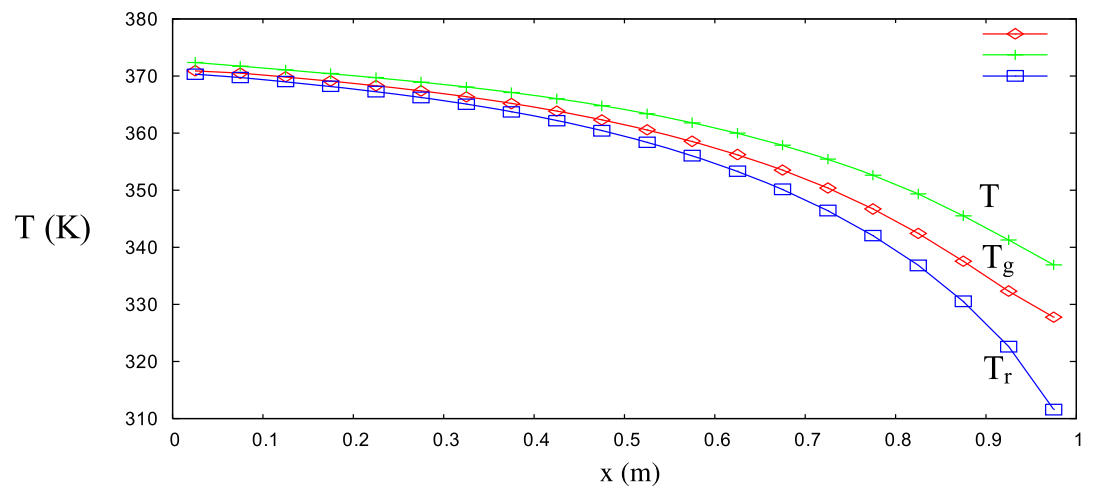

(c)

Figure 11. Effect of the porosity in the regenerator temperature distribution for (a) $\phi=0.95$, (b) $\phi=0.5$, and (c) $\phi=0.2$.

their physical properties. The geometry and several physical properties were measured directly from the PEBB prototype and are listed in Tables III-VI. The initial temperature of the PEBB for the simulations was set to be $296.3 \mathrm{~K}$.

A mesh was built to represent the computational domain for the PEBB shown in Figure 8. The convergence according to Eqn. (54) was obtained with 2000 elements, in other words, a number small enough to be classified as a sparse mesh considering it is a three-dimensional problem. Table III shows the system dimensions and the number of VEs in each of the three spatial directions.

The information on the composition of all components listed in Table IV is used to estimate equivalent densities, specific heats, thermal conductivities, and heat transfer surface ratios of the components. This adjustment is required to implement the first alternative of the VEM regarding mixed elements, that is, a mixture of homogeneous entities (substances), and to calculate uniform properties for the VE, which are defined as 


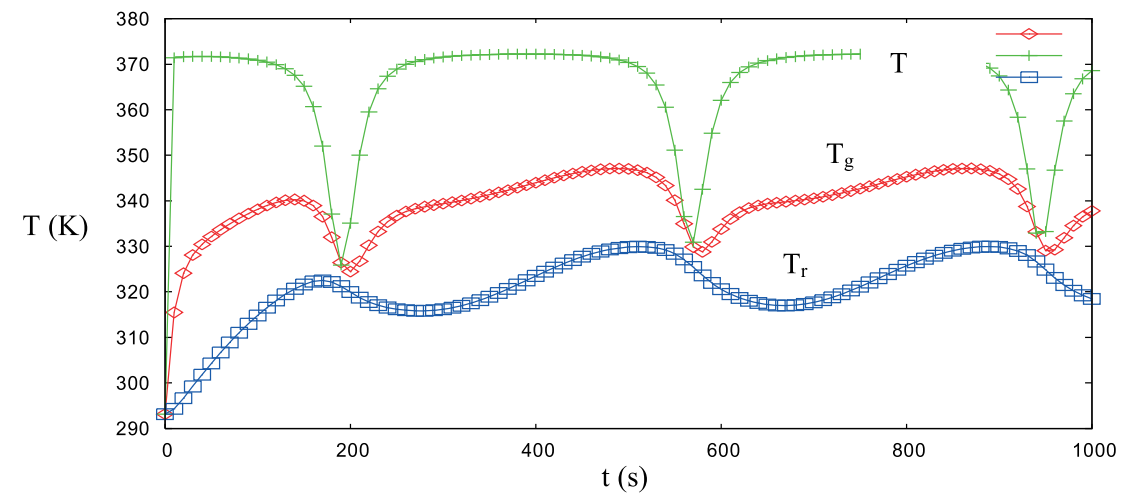

(a)

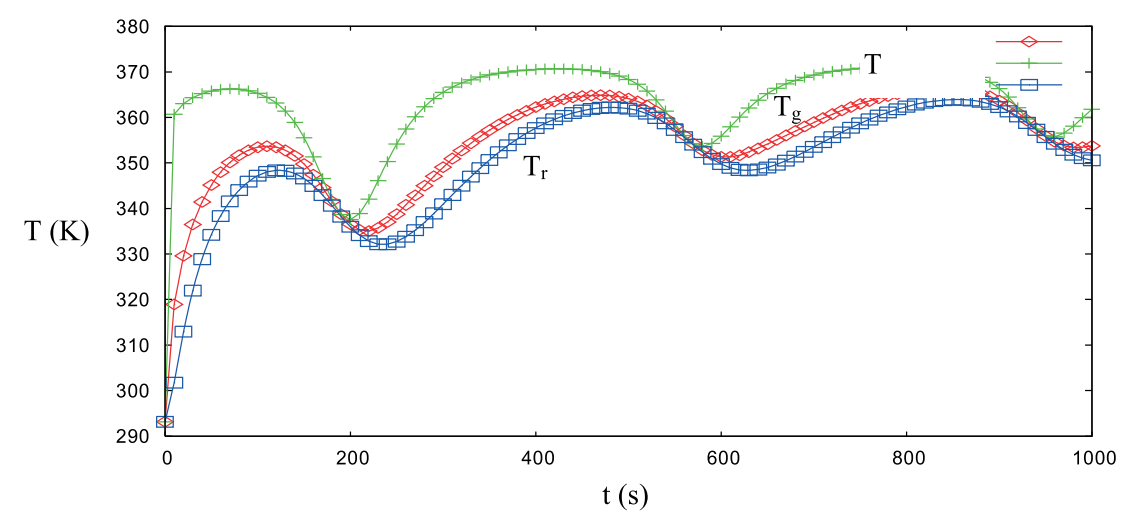

(b)

Figure 12. Temperature as a function of time in the first volume element of the regenerator when the hot stream flow rate is modeled with a periodic function: (a) $\phi=0.95$ and (b) $\phi=0.5$.

Table III. Converged mesh.

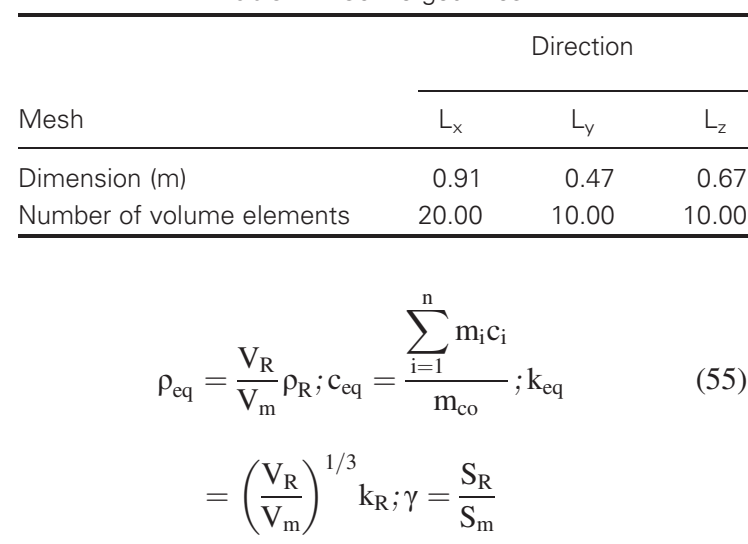

Table V. Components' dimensions and positions.

\begin{tabular}{lcccccccc}
\hline & \multicolumn{3}{c}{ Position $(\mathrm{m})$} & & \multicolumn{3}{c}{ Dimension (m) } \\
\cline { 2 - 3 } Component & $\mathrm{x}$ & $\mathrm{y}$ & $\mathrm{z}$ & & $\mathrm{L}_{x}$ & $\mathrm{~L}_{y}$ & $\mathrm{~L}_{z}$ \\
\hline Thyristors/fins & 0.3 & 0.2 & 0.35 & & 0.30 & 0.20 & 0.20 \\
Alternating current fuse & 0.7 & 0.2 & 0.35 & & 0.08 & 0.05 & 0.05 \\
Direct current fuse & 0.1 & 0.2 & 0.35 & & 0.08 & 0.05 & 0.05 \\
Capacitor & 0.3 & 0.2 & 0.05 & & 0.40 & 0.30 & 0.20 \\
Inductor & 0.7 & 0.2 & 0.35 & & 0.10 & 0.05 & 0.05 \\
\hline
\end{tabular}

where $\rho_{\mathrm{R}}$ is the actual component weighted average density; $V_{R} / V_{m}$ is the ratio of the component's physical volume to the mesh volume; $\mathrm{m}_{\mathrm{i}}$ is the mass of material $\mathrm{i}$ in the component, which is composed of $\mathrm{n}$ material types;

Table IV. Components' physical properties.

\begin{tabular}{lccccl}
\hline Component & Quantity & Volume $\left(\mathrm{m}^{3}\right)$ & Mass $(\mathrm{kg})$ & Area $\left(\mathrm{m}^{2}\right)$ & Material \\
\hline Thyristors/fins & 1 & 0.00204 & 5.526 & 0.7350 & $100 \% \mathrm{Al}$ \\
Alternating current fuse & 3 & $3.0 \mathrm{e}-5$ & 0.108 & 0.0059 & Liga Sn \\
Direct current fuse & 2 & $3.7 \mathrm{e}-5$ & 0.108 & 0.0068 & Liga Sn \\
Capacitor & 6 & 0.00099 & 1.748 & 0.0615 & $60 \% \mathrm{Al}, 10 \% \mathrm{PVC}, 30 \%$ ar \\
Inductor & 1 & 0.00512 & 14.000 & 0.1581 & $60 \% \mathrm{Cu}, 40 \% \mathrm{Fe}$ \\
\hline
\end{tabular}


Table VI. Components' heat generation rate.

\begin{tabular}{lcc}
\hline Component & $\begin{array}{r}\text { Test 1 (200 V; 24 A; } \\
\text { 4.8 kW) } \dot{Q}_{\text {gen }}\end{array}$ & $\begin{array}{c}\text { Test 2 }(279 \mathrm{~V} ; 40 \mathrm{~A} ; \\
11.12 \mathrm{~kW}) \dot{\mathrm{Q}}_{\mathrm{gen}}\end{array}$ \\
\hline Thyristors/fins & 130.0 & 182.0 \\
Alternating & 8.7 & 11.5 \\
$\begin{array}{l}\text { current fuse } \\
\text { Direct current }\end{array}$ & 3.0 & 7.7 \\
fuse & & \\
Capacitor & 0.0 & 0.0 \\
Inductor & 23.0 & 60.0 \\
Total & 164.7 & 261.2 \\
\hline
\end{tabular}

$\mathrm{m}_{\text {co }}$ is the component mass; $\mathrm{k}_{\mathrm{R}}$ is the actual component weighted average thermal conductivity; and $\gamma=S_{R} / S_{m}$ is the ratio of the component's physical heat transfer surface to the one in the mesh.

The model adjustment was performed with the $4.8-\mathrm{kW}$ PEBB power input, and it consisted of solving the IPPE using the mathematical model, that is, by turning a variable into a parameter and vice versa [32]. In order to accomplish that, a variable is imposed to the model as an input parameter, and in this study, the variables available from the experiments were the measured temperatures of the PEBB prototype.

The procedure started by selecting physical parameters as the variables to be determined. According to Eqn. (55), it was possible to measure equivalent densities, specific heats, heat transfer surface ratios, and thermal conductivities of the equipment; however, the uncertainty in the direct measurements was high. Therefore, the heat transfer surface ratio of each of the five electronic components was selected as a parameter to be adjusted using the IPPE. The numerical solution of the IPPE was obtained for the steady-state case with $4.8-\mathrm{kW}$ power setting, and the measured average temperature of each component was used as an input to the mathematical model. Then the heat transfer surface ratio for each component was calculated using the measured values as initial guesses. As a result, using the calculated $\gamma$, the average temperature of each of the five components predicted by the mathematical model matched the measured ones. The results are shown in Table VII, in which each component's physical volume-to-mesh volume ratios required by Eqn. (55) are also listed.

Table VII. Volume and heat transfer surface correction values.

\begin{tabular}{lccc}
\hline Component & No. of VEs & $V_{\mathrm{R}} N_{\mathrm{m}}$ & $\gamma$ (IPPE) \\
\hline Thyristors/fins & 90 & 0.755 & 1.940 \\
AC fuse & 3 & 0.472 & 0.410 \\
DC fuse & 2 & 0.566 & 0.437 \\
Capacitor & 96 & 1.417 & 0.882 \\
Inductor & 16 & 1.417 & 1.248 \\
\hline
\end{tabular}

VE, volume element; IPPE, inverse problem of parameter estimation; AC, alternating current; DC, direct current.

\subsubsection{Experimental validation of the PEBB model}

After the model adjustment is performed, the next step was the model experimental validation, which was performed with the 11.12-kW PEBB power setting. The calculated $\gamma$ values were then used as input to the mathematical model to numerically obtain the internal temperature distribution of the PEBB. The initial temperature for the simulations was set as $296.3 \mathrm{~K}$.

In order to investigate more deeply the accuracy of the numerical predictions of the adjusted model in comparison with the collected experimental data for the PEBB 11.12-kW setting, Figure 13 provides simulation and experimental results for the average temperatures of two components that generate heat in the system, that is, a set of thyristors/fins and inductor. In the experimental results, the uncertainties were calculated according to the largest observed value for $\mathrm{U}_{\mathrm{T}} / \mathrm{T}$ during the transient-state to steady-state evolution of the measurements, which was used to draw the error bars shown in all experimental points for consistency, as described by Dilay et al. [16].

Figure 13a shows that the simulated temperature curves lie within the error bars for the steady state and evolve at a higher rate during the transient state for the

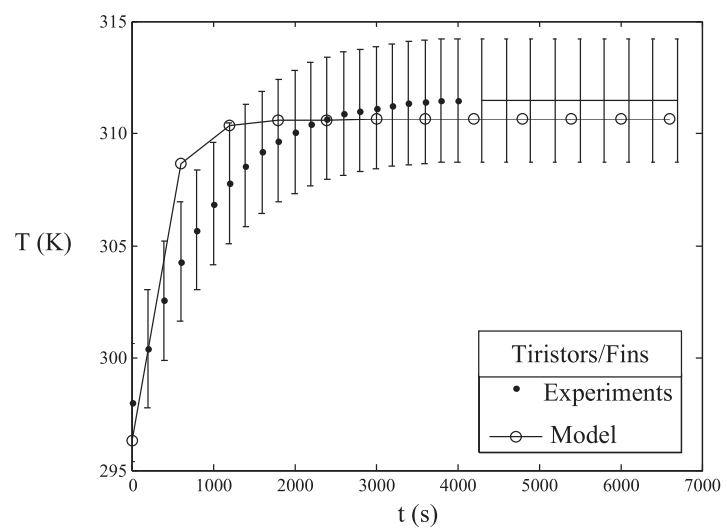

(a)

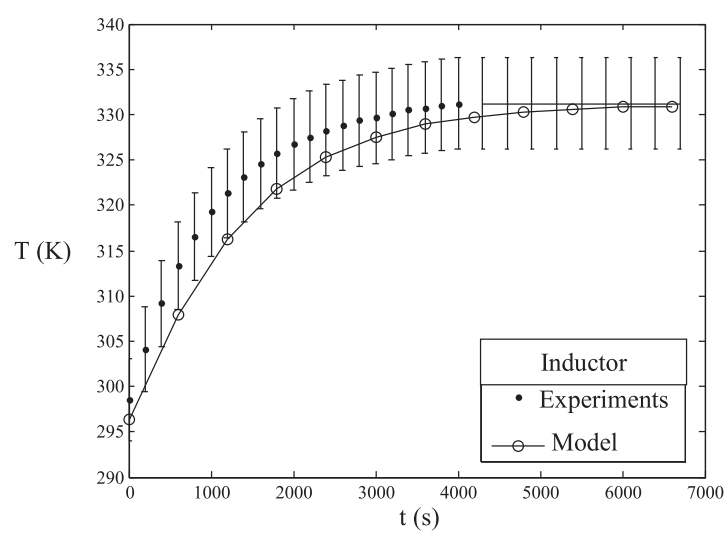

(b)

Figure 13. Temperature of (a) the thyristors/fins set and (b) the inductor. 
thyristors/fins set, but mostly remaining within the margin of error. This is probably due to a slight underestimation of the total inertia (mass) of the thyristors/ fins set. A similar phenomenon was observed for the inductor, as the results of Figure $13 \mathrm{~b}$ show, but in this case, the inductor inertia must have been slightly overestimated. These two components are the ones that generate the most heat in the PEBB; therefore, it is

$\mathrm{T}(\mathrm{K})$

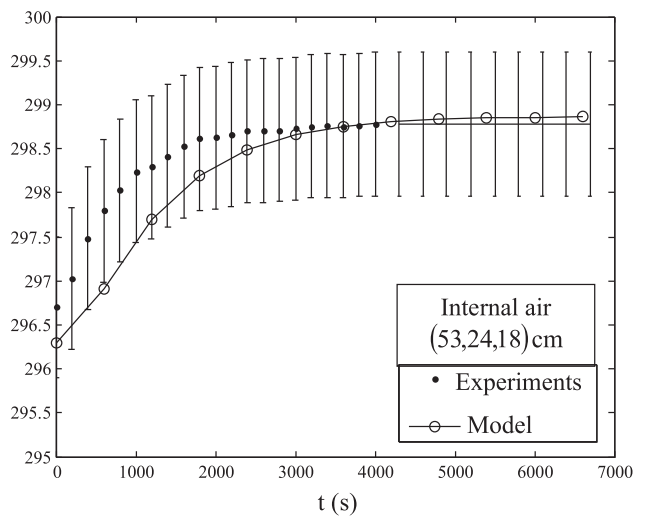

(a)

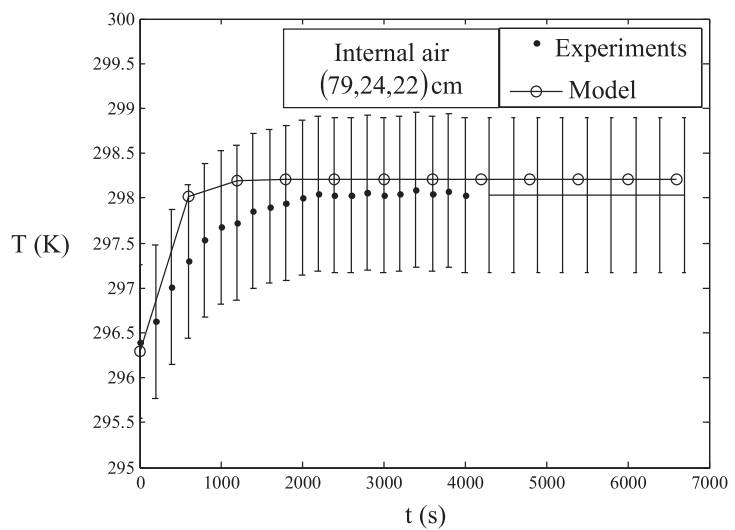

(b)

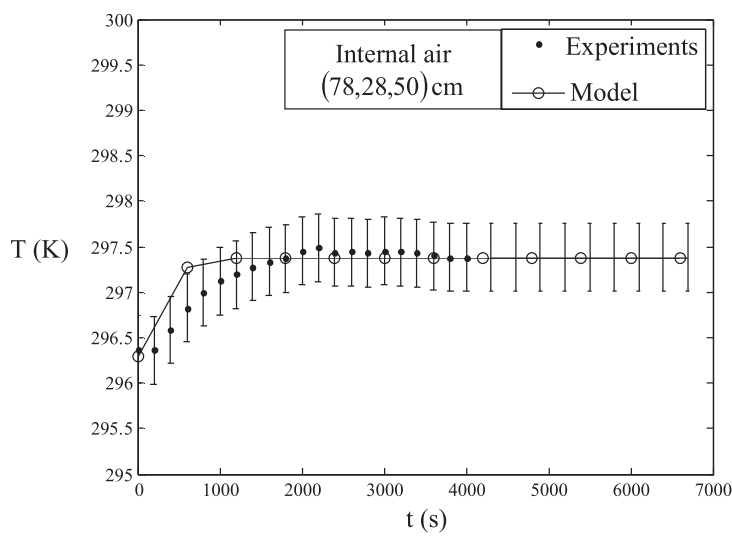

(c)

Figure 14. Temperature of the internal air at (a) $(53,24,19) \mathrm{cm}$, (b) $(79,24,22) \mathrm{cm}$, and (c) $(78,28,50) \mathrm{cm}$ considered that the simulated and experimental curves are in very good qualitative and quantitative agreement, mainly if the analysis prioritizes the assessment to steady-state conditions.

The simulated and experimental temperatures for the internal air at three different locations in the PEBB are shown in Figure 14. All predicted temperature values lie within the error bars for the transient-state to steady-state evolution in the three locations. Therefore, these results test and validate the assumptions made to write Eqn. (52) that predict the convection heat transfer rate extracted by the fan-driven air stream that flows across the PEBB, that is, an approximate air flow field is capable of allowing the simplified mathematical model to produce accurate thermal predictions.

Finally, as an example of the model application in a transient simulation, a transient analysis is conducted numerically with the model. Figure 15 shows the thermal transient response of the PEBB when the total heat generation mode changes from $\dot{\mathrm{Q}}_{\text {gen,tot }}=164.7 \mathrm{~W}$ to $\dot{\mathrm{Q}}_{\mathrm{gen}, \text { tot }}=261.2 \mathrm{~W}$, then back to $\dot{\mathrm{Q}}_{\mathrm{gen}, \mathrm{tot}}=164.7 \mathrm{~W}$, and finally goes up to $\dot{\mathrm{Q}}_{\text {gen,tot }}=391.8 \mathrm{~W}$, which is a load $50 \%$ higher than $\dot{\mathrm{Q}}_{\text {gen,tot }}=261.2 \mathrm{~W}$. The total simulation time was close to $20,000 \mathrm{~s}$. Besides information on the time required to achieve new steady-state conditions, the results demonstrate that the components' temperature vary significantly from one heating mode to another, an effect that becomes increasingly important as total heat generation increases, whereas internal air average temperature varies only slightly for all heating modes. This is explained by the fact that air has a low thermal conductivity and therefore poor thermal contact with the components. Such an effect is commonly disregarded in current electronic packaging practice, which usually specifies operating conditions for components based on internal air average temperature. Therefore, in spite of low internal air average

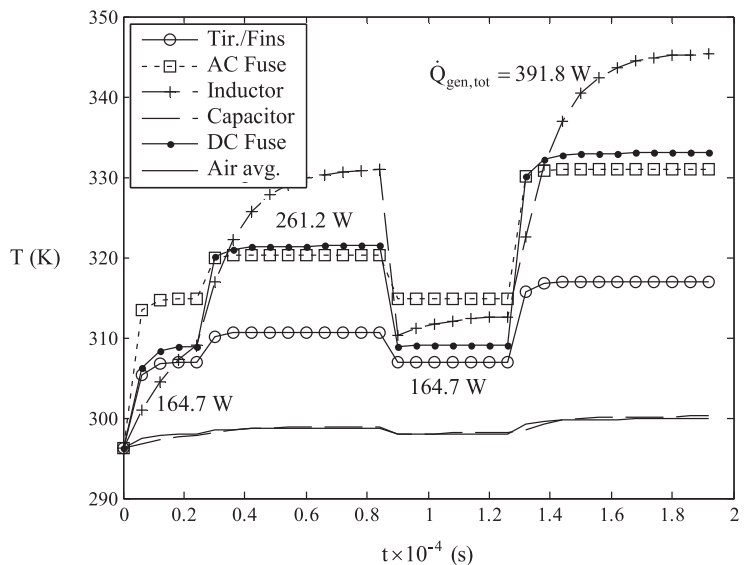

Figure 15. The effect of the transient change of total heat generation mode on the power electronic building block thermal response. 
temperature, component failure could occur, as the total heat generation increases, as the present model demonstrates.

\subsection{Thermal management of a notional all-electric ship}

Once the mathematical model for the thermal management was experimentally validated with the PEBB, it is expected that the results are reliable for the analysis of similar systems. Therefore, the model is used in this section to simulate the thermal behavior of an allelectric ship. In order to obtain the internal ship temperature distribution, a notional all-electric ship configuration for the so-called baseline medium-voltage direct current architecture, presented in Figure 10, was used. Instead of using separate small and medium loads from the given database [33], the loads were grouped in their respective zones with an estimated total heat dissipation rate. In addition to small and medium loads, all large loads shown in Figure 10 were individually considered in the simulations.

\subsubsection{Mesh generation}

The mesh needed to perform the numerical simulation with the proposed model was generated with a technique that consists of three stages: (i) mesh generation with hexahedral blocks enveloping the system under analysis; (ii) definition of the boundary of the computational domain (e.g., ship hull) via ray tracing; and (iii) insertion of equipment. The technique was proposed and described in detail by Dilay et al. [34], and it is summarized in a schematic diagram in Figure 16a, which illustrates each stage in a chronological order.

The ship was divided into small compartments (VEs), and equipment was placed in one or more grid elements according to their physical dimensions. The procedure was designed to start with the $\mathrm{x}, \mathrm{y}$, and $\mathrm{z}$ coordinates of a particular item, listed in the notional data [33], which are then compared with the midpoint coordinates of all grid elements in order to determine to which grid elements the equipment should be allocated.

The ship discretization for vemESRDC used the standard coordinate system showed in Figure 16b. The number of divisions in the mesh resulted from the accuracy of the numerical refinement procedure to obtain a converged mesh following the criterion of Eqn. (54). Therefore, the number of decks and other divisions shown in Figure $16 \mathrm{~b}$ is only a schematic representation for clarity.

The spatial distribution of all pieces of equipment inside the ship is listed in Table VIII. Arbitrary locations and dimensions were selected to conduct the simulations presented in this work. However, the equipment locations and dimensions can easily be changed in the input data according to any mechanical notional ship design.
In the example under analysis, the converged grid had a total of 7725 elements. This result can be considered as a sparse mesh, considering the ship dimensions listed in Table IX, along with the information on the converged mesh.

\subsubsection{Simulation conditions}

The external conditions considered in the two simulations performed in this work are frontal wind speed of $10 \mathrm{~m}$ $\mathrm{s}^{-1}$, air temperature of $260 \mathrm{~K}\left(10^{\circ} \mathrm{F}\right)$ and $305 \mathrm{~K}\left(90^{\circ} \mathrm{F}\right)$, seawater temperature of 280 and $288 \mathrm{~K}$, and local average sun direct radiation of $400 \mathrm{~W} \mathrm{~m}^{-2}$ (top, east, and north faces) and $0 \mathrm{~W} \mathrm{~m}^{-2}$ (west and south faces). The list of equipment in the notional ship and their heat generation rates is shown in Table VIII, where equipment positions and their respective sizes are also shown.

In both scenarios analyzed in this work, it was assumed that the ship's draft was $10 \mathrm{~m}$, the initial temperature was $288 \mathrm{~K}$, and the assumed known initial relative humidity was $\phi_{\mathrm{i} 0}=0.8(80 \%)$.

Regarding the thermal design, seawater heat exchangers with known global heat transfer coefficients, $\mathrm{U}\left(\mathrm{W} \mathrm{m}^{-2}\right.$ $\left.\mathrm{K}^{-1}\right)$, and areas, $\mathrm{A}\left(\mathrm{m}^{2}\right)$, were allocated to zones 1,2 , $3-5$, and 4, such that $(\mathrm{U}, \mathrm{A})=(100,100),(100,500)$, $(100,1000)$, and $(100,100)$, respectively. Also, chilled water units were allocated to zones $1,2,3-5$, and 4 , with known refrigeration capacity rates of 100, 500, 500, and $100 \mathrm{~kW}$, respectively. Finally, equal freshwater and seawater total mass flow rates of $8,60,60$, and $10 \mathrm{~kg} \mathrm{~s}^{-1}$ were selected to zones $1,2,3-5$, and 4, respectively.

In addition to steady-state simulations, transient simulations were also performed to obtain dynamic responses of the ship. Dynamic simulations were performed under three different conditions: (i) variation in total heat load inside the ship; (ii) variation in freshwater cooling mass flow rate; and (iii) variation in chilled water unit cooling capacity.

The simulations consisted of starting the test with the selected parameter at $50 \%$ of its original value for $10,000 \mathrm{~s}$, then changing it to $100 \%$ for another $10,000 \mathrm{~s}$, returning it to $50 \%$ for the next $10,000 \mathrm{~s}$, and finally changing it to $150 \%$ of its original value for a sufficient period to attain steady state. Only one parameter was varied for each test, and a set of results was generated for each parameter, resulting in temperature variation curves for each ship equipment over a certain period.

External air and water temperatures are set to be 305 and $288 \mathrm{~K}$, respectively, for analyzing the ship dynamic response. Between the two cases analyzed in this study, this is the case with the highest surrounding temperatures, therefore the most challenging one for ship thermal management.

For steady-state cases, the simulation took between 5 and 10 min until convergence was achieved, that is, until $\|\partial \mathrm{T} / \partial \mathrm{t}\| \leq 10^{-3}$, where $\mathrm{T}=\left(\mathrm{T}_{1}, \mathrm{~T}_{2}, \ldots, \mathrm{T}_{\mathrm{n}}\right)^{\mathrm{T}}$ is the temperature vector, in which each component represents the temperature at the center of each VE. For transient cases, 


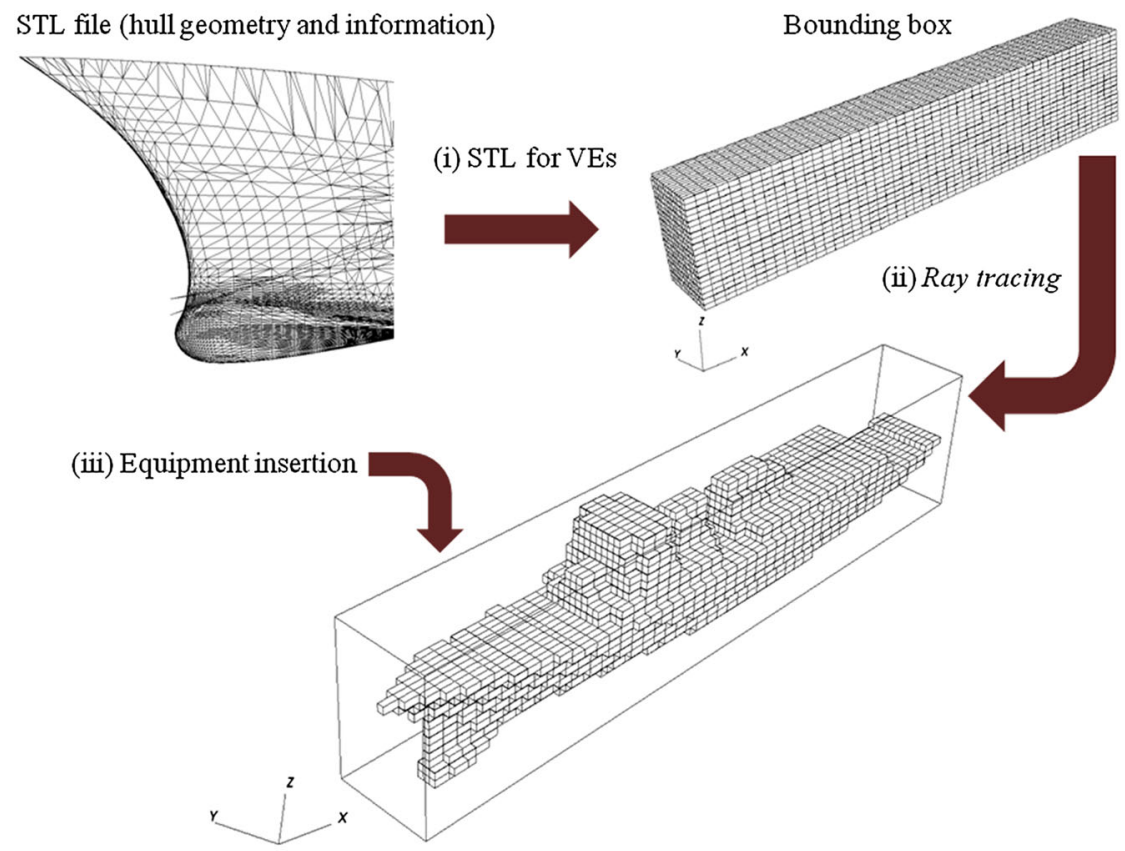

(a)

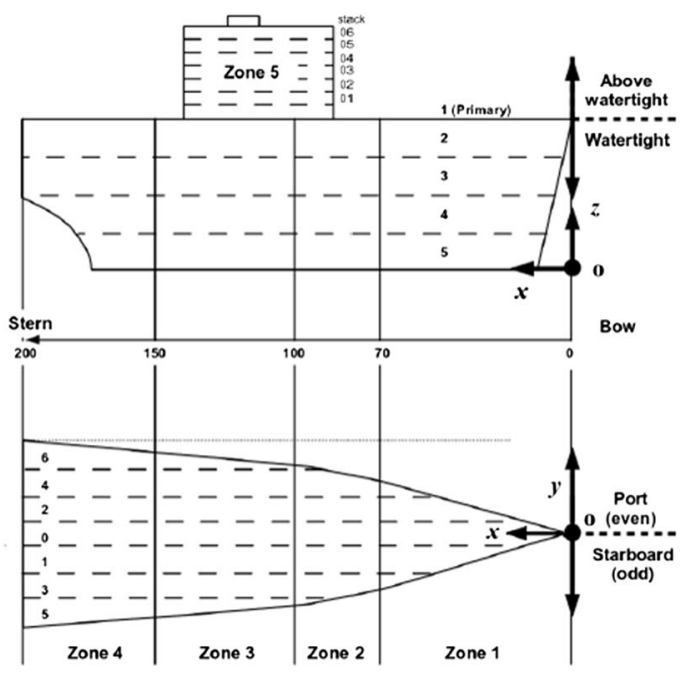

(b)

Figure 16. (a) Summary of mesh generation process for the notional all-electric ship with external design of destroyer DDG-51 [34] and (b) ship zone distribution and coordinate system [34].

the simulation took about $50 \mathrm{~min}$. The computer used in this simulation had an Intel Pentium Dual-Core T2330 processor with $4 \mathrm{~GB}$ RAM and the operating system 64-bit Linux Fedora 19.

\subsubsection{Steady-state simulation}

The resulting external temperature field for the first simulation in a $260-\mathrm{K}$ day is shown in Figure 17a. The maximum observed temperature within the ship was $348 \mathrm{~K}$, which demonstrates the effectiveness of the freshwater and seawater cooling strategies to extract the large heat generation rates shown in Table VIII out of the ship and keeping the cooling water temperature below boiling point throughout the ship. The constraints in this model were set to maintain chilled water below boiling; these constraints can be changed as required for actual system specifications. The results are further analyzed internally in the ship midplane in Figure 17b. As expected, the highest temperatures occur in zones 2 and 3 where heat generation is higher.

The resulting external temperature field for the second simulation in a $305-\mathrm{K}$ day is shown in Figure $17 \mathrm{c}$. The 
Table VIII. Positions and dimensions of components in an all-electric ship [34].

\begin{tabular}{|c|c|c|c|c|c|c|c|c|c|}
\hline \multirow[b]{2}{*}{ No. } & \multirow[b]{2}{*}{ Equipment } & \multirow[b]{2}{*}{ Zone } & \multirow[b]{2}{*}{ Heat generation $(\mathrm{kW})$} & \multicolumn{3}{|c|}{ Position } & \multicolumn{3}{|c|}{ Dimension } \\
\hline & & & & $x(m)$ & $y(m)$ & $z(m)$ & $L_{x}(m)$ & $L_{y}(m)$ & $L_{z}(m)$ \\
\hline 1 & SWHX_ZONE-1 & 1 & 0.0 & 27.0 & 1.7 & 0.2 & 5.0 & 2.0 & 2.0 \\
\hline 2 & CWU_ZONE-1 & 1 & -100.0 & 27.0 & -2.3 & 0.2 & 5.0 & 2.0 & 2.0 \\
\hline 3 & Lump2_ZONE-1 & 1 & 10.0 & 20.0 & 1.7 & 9.0 & 5.0 & 2.0 & 2.0 \\
\hline 4 & Lump3_ZONE-1 & 1 & 415 & 27.0 & 1.7 & 6.0 & 5.0 & 2.0 & 2.0 \\
\hline 5 & Lump1_ZONE-1 & 1 & 36.3 & 20.0 & 1.7 & 6.0 & 5.0 & 2.0 & 2.0 \\
\hline 6 & SWHX_ZONE-2 & 2 & 0.0 & 50.0 & 0.0 & 0.2 & 5.0 & 3.0 & 2.0 \\
\hline 7 & CWU_ZONE-2 & 2 & -500.0 & 50.0 & -6.0 & 0.2 & 5.0 & 2.0 & 2.0 \\
\hline 8 & STBD_M_DCS_ZONE-2 & 2 & 730.0 & 50.0 & 6.0 & 9.0 & 5.0 & 3.0 & 2.0 \\
\hline 9 & STBD_M_ZONE-2 & 2 & 0.0 & 50.0 & 0.0 & 9.0 & 5.0 & 3.0 & 2.0 \\
\hline 10 & Lump2_ZONE-2 & 2 & 0.0 & 50.0 & -6.0 & 12.0 & 5.0 & 3.0 & 2.0 \\
\hline 11 & Lump3_ZONE-2 & 2 & 486.0 & 50.0 & 0.0 & 4.0 & 5.0 & 3.0 & 2.0 \\
\hline 12 & Lump1_ZONE-2 & 2 & 100.0 & 50.0 & -6.0 & 4.0 & 5.0 & 3.0 & 2.0 \\
\hline 13 & MTG2_ZONE-2 & 2 & 720.0 & 50.0 & -6.0 & 9.0 & 5.0 & 2.0 & 2.0 \\
\hline 14 & PCM_AC-DC_ZONE-2 & 2 & 705.0 & 50.0 & 6.0 & 4.0 & 5.0 & 2.0 & 2.0 \\
\hline 15 & PLDCS_ZONE-2 & 2 & 36.7 & 60.0 & 0.0 & 12.0 & 5.0 & 3.0 & 2.0 \\
\hline 16 & Pulse_Load_ZONE-2 & 2 & 0.0 & 50.0 & 0.0 & 12.0 & 5.0 & 3.0 & 2.0 \\
\hline 17 & STBD_MD_DCS_ZONE-2 & 2 & 744.0 & 50.0 & 3.0 & 0.2 & 5.0 & 3.0 & 2.0 \\
\hline 18 & STBD_MD_ZONE-2 & 2 & 0.0 & 60.0 & 0.0 & 0.2 & 5.0 & 3.0 & 2.0 \\
\hline 19 & SWHX_ZONE-3-5 & 3 & 0.0 & 70.5 & 1.8 & 0.2 & 5.0 & 3.0 & 2.0 \\
\hline 20 & CWU_ZONE-3-5 & 3 & -500.0 & 70.5 & -4.2 & 0.2 & 5.0 & 2.0 & 2.0 \\
\hline 21 & MTG1_ZONE-3 & 3 & 720.0 & 100.5 & -4.2 & 0.2 & 5.0 & 2.0 & 2.0 \\
\hline 22 & PCM_AC-DC-1_ZONE-3 & 3 & 705.6 & 93.5 & 7.8 & 9.0 & 5.0 & 3.0 & 2.0 \\
\hline 23 & ATG1_ZONE-3 & 3 & 0.2 & 93.5 & 1.8 & 9.0 & 5.0 & 3.0 & 2.0 \\
\hline 24 & PCM_AC-DC-2_ZONE-3 & 3 & 153.6 & 93.5 & 4.8 & 0.2 & 5.0 & 2.0 & 2.0 \\
\hline 25 & Port-Motor-Drive_ZONE-3 & 3 & 744.0 & 93.5 & -4.2 & 9.0 & 5.0 & 3.0 & 2.0 \\
\hline 26 & Port_Motor_ZONE-3 & 3 & 730.0 & 93.5 & -4.2 & 4.0 & 5.0 & 3.0 & 2.0 \\
\hline 27 & Lump2_ZONE-3 & 3 & 0.0 & 102.0 & 1.8 & 14.0 & 5.0 & 3.0 & 2.0 \\
\hline 28 & Lump3_ZONE-3 & 3 & 583.5 & 93.5 & 1.8 & 4.0 & 5.0 & 3.0 & 2.0 \\
\hline 29 & Lump1_ZONE-3 & 3 & 200.0 & 102.0 & 1.8 & 0.2 & 5.0 & 3.0 & 2.0 \\
\hline 30 & SWHX_ZONE-4 & 4 & 0.0 & 110.0 & 1.8 & 0.2 & 5.0 & 3.0 & 2.0 \\
\hline 31 & CWU_ZONE-4 & 4 & -100.0 & 110.0 & -4.2 & 0.2 & 5.0 & 2.0 & 2.0 \\
\hline 32 & PCM_AC-DC_ZONE-4 & 4 & 153.6 & 110.0 & 7.8 & 5.2 & 5.0 & 2.0 & 2.0 \\
\hline 33 & ATG2_ZONE-4 & 4 & 160.0 & 130.0 & 1.8 & 4.0 & 5.0 & 2.0 & 2.0 \\
\hline 34 & ESPCM_DC-DC_ZONE-4 & 4 & 120.0 & 130.0 & 5.8 & 6.0 & 5.0 & 2.0 & 2.0 \\
\hline 35 & Lump3_ZONE-4 & 4 & 444.8 & 110.0 & -4.2 & 11.0 & 5.0 & 3.0 & 2.0 \\
\hline 36 & Lump2_ZONE-4 & 4 & 0.0 & 120.0 & 7.8 & 0 & 5.0 & 3.0 & 2.0 \\
\hline 37 & Lump1_ZONE-4 & 4 & 50.0 & 120.0 & -4.2 & 0 & 5.0 & 3.0 & 2.0 \\
\hline 38 & Radar_PCM-DC-DC-1_ZONE-5 & 5 & 60.0 & 65.0 & 1.8 & 14.0 & 3.0 & 2.0 & 2.0 \\
\hline 39 & Radar_ZONE-5 & 5 & 562.5 & 65.0 & -2.0 & 17.0 & 3.0 & 2.0 & 2.0 \\
\hline 40 & Radar_PCM-DC-DC-2_ZONE-5 & 5 & 60.0 & 65.0 & 2.0 & 17.0 & 3.0 & 2.0 & 2.0 \\
\hline 41 & Lump3_ZONE-5 & 5 & 30.0 & 65.0 & 1.0 & 19.0 & 3.0 & 2.0 & 2.0 \\
\hline 42 & Lump2_ZONE-5 & 5 & 0.0 & 75.0 & 1.0 & 19.0 & 3.0 & 2.0 & 2.0 \\
\hline 43 & Lump1_ZONE-5 & 5 & 30.0 & 60.0 & 0.0 & 14.0 & 3.0 & 2.0 & 2.0 \\
\hline
\end{tabular}

Table IX. Notional ship dimensions and mesh size [34].

\begin{tabular}{lcc}
\hline Direction & Length $(\mathrm{m})$ & Divisions \\
\hline Bow to stern & 153.50 & 50 \\
Port to starboard & 20.60 & 15 \\
Keel to the waterline & 14.62 & 5 \\
Waterline to the superstructure top & 14.62 & 5 \\
\hline
\end{tabular}

maximum temperature within the ship was $356.2 \mathrm{~K}$, which demonstrates the effectiveness of the water cooling strategies to extract heat out of the ship, even in a hotter day than the previous simulation. In order to further reduce this temperature, the air conditioning cooling capacity should be increased. In this simulation, it is possible to notice the water line on the hull through the surface temperature distribution.

Next, the results are analyzed internally in the ship midplane in Figure 17d. Again, the highest temperatures 

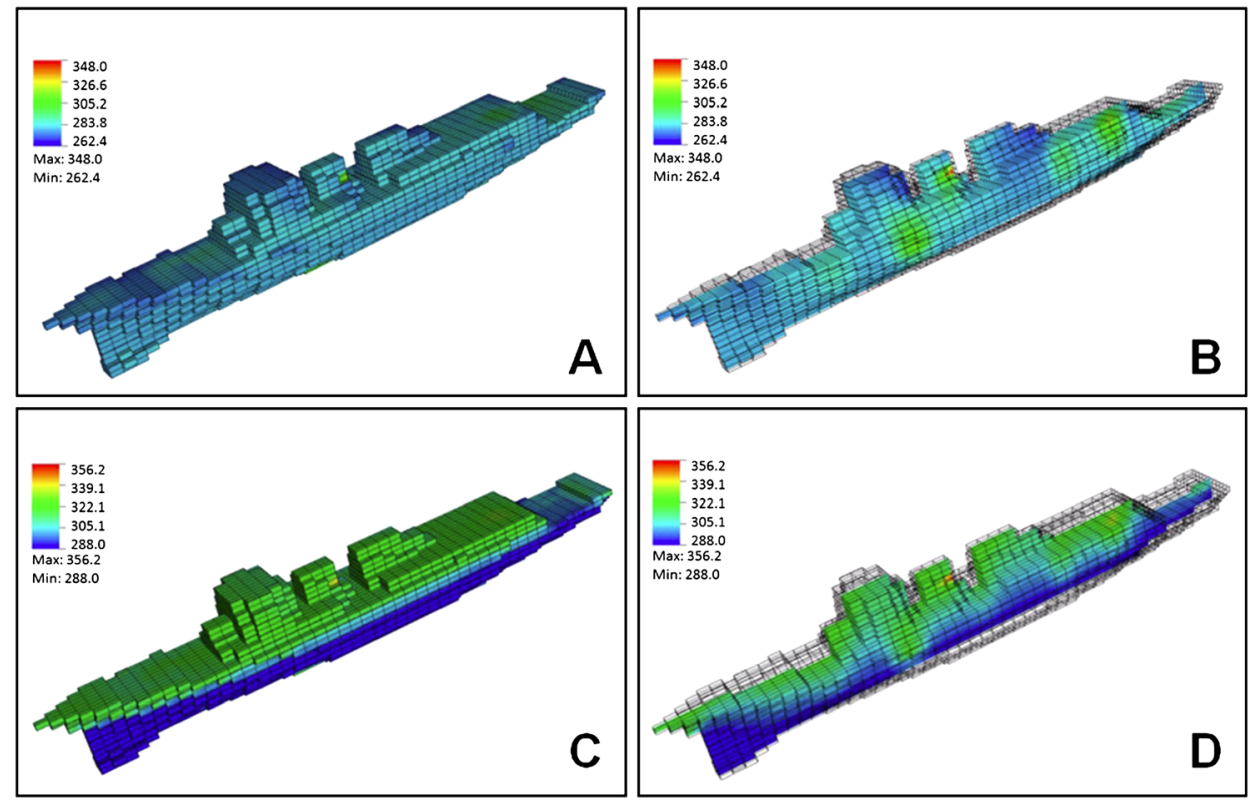

Figure 17. Ship external and midplane temperature fields for (a, b) 260-K day and (c, d) 305-K day, respectively.

occur in zones 2 and 3 where heat generation is higher. Figure 18 illustrates the resulting humidity field in the ship's midplane. It is interesting to note that as the temperature increases, relative humidity decreases in air VEs, as is thermodynamically expected. It is crucial to know the relative humidity field to prevent condensation in electronic devices; that is, high relative humidity should be avoided (close to $100 \%$ ). Also, in solid VEs, the model sets $\varphi_{i}=0$; hence, it is possible to identify where solid equipment items are located based on the resulting relative humidity distribution.

\subsubsection{Dynamic simulation with variation in total power}

As examples of possible dynamic simulations of an allelectric ship, temperature variation curves of four equipment as functions of time are shown, that is, STBDM-DCS in zone 2, radar in zone 5, and board motor drive and board motor in zone 3 . These equipment depict

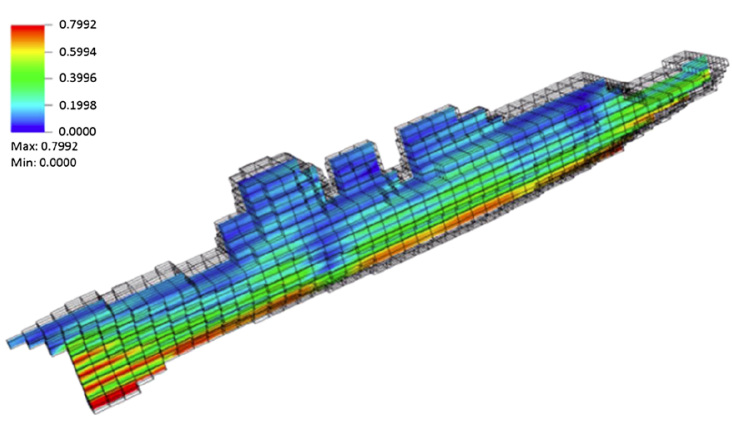

Figure 18. Ship midplane relative humidity (305-K day). the largest temperature variations in the simulation and thus selected to be analyzed for synthesis and prioritization purposes. Likewise, temperature curves for the other 39 equipment are also available in all simulations. The computer took $3000 \mathrm{~s}$ to simulate 80,000 s of real time.

Figure 19a,b shows the temperature variation over time due to the total power variation of $50 \%, 100 \%$, $50 \%$, and $150 \%$ of the original value listed in Table VIII, in intervals of $10,000 \mathrm{~s}$, allowing for stabilization in the last power setting. Note that the time required for the temperature to reach steady state is about $20 \mathrm{~h}$, that is, $8 \times 10^{4} \mathrm{~s}$. This is due to the large mass and, consequently, ship thermal inertia. Note that the simulations account for the components' thermal interaction with one another. This is one of the differences of the VEM with respect to other numerical methods. Usually, in simulations of this size, the interactions between components inside the system under analysis are not taken into account.

Figure 19a (left) shows the initial temperature of the STBD-M-DCS component in zone 2 at $288 \mathrm{~K}$ rising to $304 \mathrm{~K}$. At this point, the total ship power was increased from $50 \%$ to $100 \%$ of its original value listed in Table VIII, as shown by the discontinuity in the derivative of the curve. When the ship temperature reached close to $330 \mathrm{~K}$ in $10,000 \mathrm{~s}$, the total power was reduced to $50 \%$, and the temperature dropped to $312 \mathrm{~K}$. Finally, the total power was raised to $150 \%$, and the simulation stopped when the steady state was attained after $40,000 \mathrm{~s}$, and the temperature stabilized a little above $370 \mathrm{~K}$.

Comparison of the curves in Figure 19a (right) with those in Figure 19a (left) shows that the curves in 

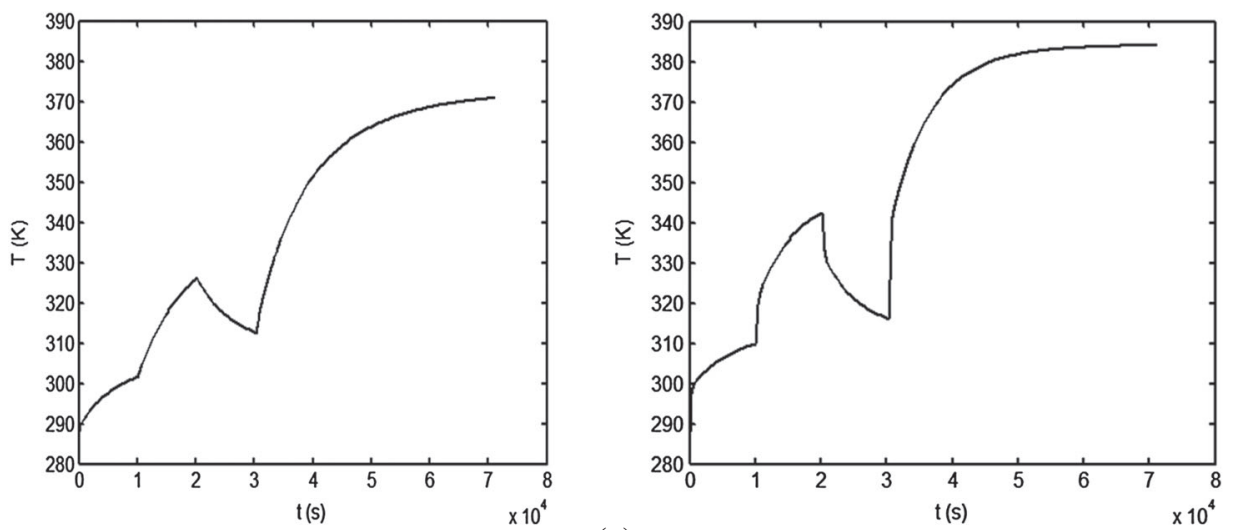

(a)
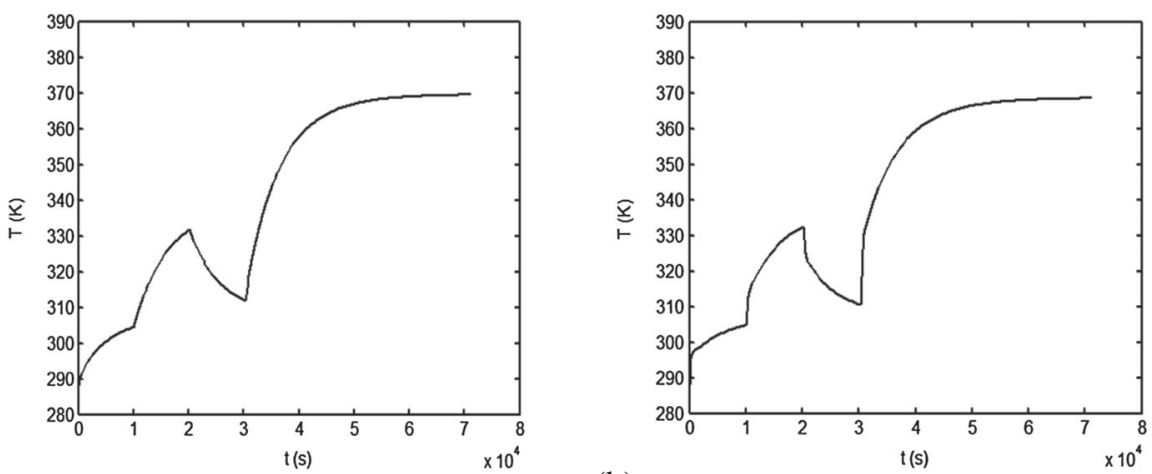

(b)

Figure 19. Temperature variation of (a) STBD-M-DCS zone 2 (left) and in radar zone 5 (right) and (b) on-board motor drive zone 3 (left) and on-board motor zone 3 (right), as a function of the total equipment power variation from $50 \%, 100 \%, 50 \%$, and $150 \%$ of the original value.

Figure 19a (right) reached higher peak temperatures, with a greater slope, which shows that the radar in zone 5 has a lower thermal inertia than the STDB-M-DCS in zone 2 .

A similar analysis to that of Figure 19a is shown in Figure 19b, in which the temperature variations of the motor drive and on-board motor in zone 3 are shown, respectively. Variation in total dissipated power of $50 \%$, $100 \%, 50 \%$, and $150 \%$ resulted in temperature curves with peaks at $100 \%$ and at $150 \%$ of its original power when steady state was reached close to $370 \mathrm{~K}$. The total computational time was $3000 \mathrm{~s}$.

\subsubsection{Dynamic simulation with variation in freshwater cooling mass flow rate}

The variation in freshwater mass flow rates of $50 \%$, $100 \%, 50 \%$, and $150 \%$ with respect to the nominal mass flow rate in intervals of $10,000 \mathrm{~s}$ resulted in curves shown in Figure 20. Figure 20a shows that the initial temperature of STBD-M-DCS in zone 2 was at $288 \mathrm{~K}$. In the first $10,000 \mathrm{~s}$ of simulation, with a freshwater mass flow rate of $50 \%$ of the nominal value, the temperature reached $340 \mathrm{~K}$. Increasing the flow to $100 \%$ was not enough to lower the temperature; hence, the temperature hardly changed in the following $20,000 \mathrm{~s}$ of the simulation. Next, the mass flow rate was reduced to $50 \%$, and the temperature went up to $365 \mathrm{~K}$ and decreased to $320 \mathrm{~K}$ when the flow rate was increased to $150 \%$ of its nominal value.

Figure 20b illustrates how the radar is most sensitive to the change in cooling water flow rate. This component achieves a peak temperature of $395 \mathrm{~K}$ when the flow rate is reduced to $50 \%$ of the nominal value. The temperature drops rapidly to $335 \mathrm{~K}$ when the flow rate increases to $150 \%$ due to the component's low thermal inertia.

The dynamic responses of the on-board motor and its drive in zone 3 with respect to different cooling water flow rates are shown in Figure 20c and d. The peak temperature for both components is a little above $370 \mathrm{~K}$, that is, when the flow rate is reduced to $50 \%$ for the second time. When the flow rate is increased to $150 \%$ of the nominal value, the temperature decreased until the steady-state temperature of $320 \mathrm{~K}$ was reached after $40,000 \mathrm{~s}$. It is observed that the motor shows a more abrupt temperature decrease than the drive. 


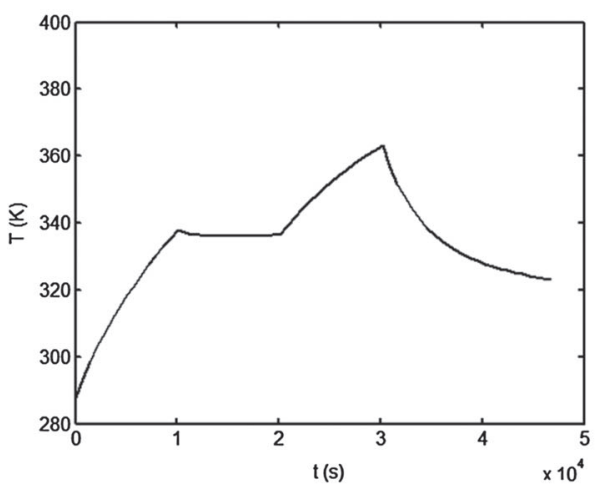

(a)

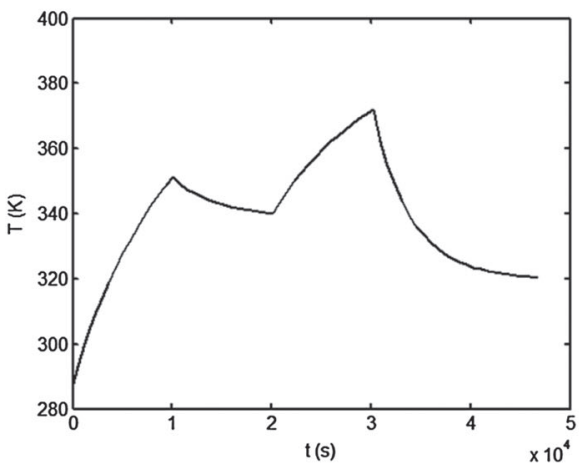

(c)

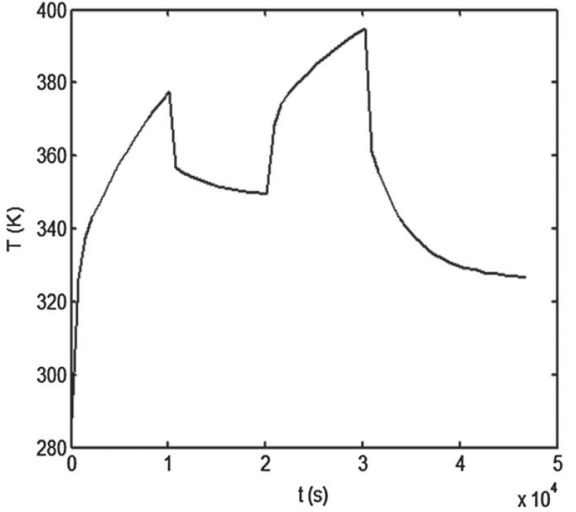

(b)

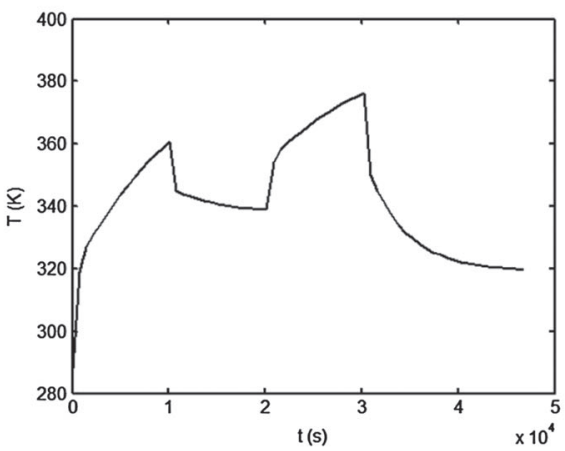

(d)

Figure 20. Temperature variation of (a) STBD-M-DCS zone 2, (b) radar zone 5, (c) on-board motor drive, and (d) on-board motor zone 3 , as a function of freshwater mass flow rate variation from $50 \%, 100 \%, 50 \%$, and $150 \%$ of the nominal flow rate in intervals of 10,000 s.

\section{CONCLUSION}

In this paper, a volume element model (VEM) was presented in a general way for mathematical modeling in energy systems engineering, that is, systems that are formed by multiple subsystems (each of them with particular characteristics). These systems interact with each other by mass and energy transfer, which can also be transferred from one subsystem to another and the system as a whole.

Mathematical models were developed for practical engineering problems, in order to serve as VEM application examples: (i) regenerative heat exchanger; (ii) PEBB; and (iii) thermal management of an all-electric ship. From these analyses, the following conclusions were drawn:

1. The regenerative heat exchanger model demonstrated how VEM allowed for the coexistence of solid and fluid components, that is, in different phases within the same VE in the analysis of the complete system.

2. The PEBB model was adjusted and experimentally validated.

3. It was possible to perform a parametric analysis of the PEBB and of an all-electric ship, using the adjusted and experimentally validated PEBB model.

4. It takes less than $10 \mathrm{~min}$ to analyze steady-state behavior of an all-electric ship and less than $50 \mathrm{~min}$ to obtain the dynamic response, that is, for the largest system considered in this study.

5. Thermal and relative humidity responses of a complete notional all-electric ship were evaluated, and the model was capable of including the cooling of all ship zones with refrigerant circulation.

From the VEM theoretical approach and the cases analyzed in this paper, it is verified that the method not only allowed for the calculation of global quantities for each subsystem (as in the models of classical thermodynamics) but was also capable of obtaining accurately the spatial and temporal distributions of desired quantities, that is, according to non-equilibrium thermodynamics. This was achieved by dividing each subsystem into smaller regions, called VEs, which represented the fundamental regions (indivisible) with uniform values in the model. Possibly, the main innovative feature of the VEM is the fact that it is possible for solid and fluid components to coexist in the same VE, that is, in different phases. The objective is to model complex systems, containing subsystems with very specific features, while including all physical phenomena of interest in the mathematical model, which can then be solved with the shortest possible computational time. As a result, the VEM is expected 
to be an efficient methodology for design, simulation, control, and optimization in energy systems engineering.

\section{NOMENCLATURE}

\begin{tabular}{|c|c|}
\hline A & $=$ area, $\mathrm{m}^{2}$ \\
\hline $\mathrm{c}$ & $=$ specific heat, $\mathrm{J} \mathrm{kg}^{-1} \mathrm{~K}^{-1}$ \\
\hline $\mathrm{C}$ & $=$ heat capacity rate, $\mathrm{W} \mathrm{K}^{-1}$ \\
\hline $\mathrm{C}_{\mathrm{a}}$ & $=$ area correction factor, Eqn. (42) \\
\hline $\mathrm{COP}$ & $=$ coefficient of performance \\
\hline $\mathrm{d}$ & $=$ diameter, $\mathrm{m}$ \\
\hline $\mathrm{D}$ & $=$ diameter, $\mathrm{m}$; outer tube diameter, $\mathrm{m}$ \\
\hline LTE & $=$ local truncation error \\
\hline VE & $=$ volume element \\
\hline $\mathrm{g}$ & $=$ gravity, $\mathrm{ms}^{-2}$ \\
\hline$\dot{\mathrm{G}}$ & $\begin{aligned}= & \text { rate of change in physical quantity/variable } \\
& \text { with respect to time }\end{aligned}$ \\
\hline h & $\begin{aligned}= & \text { convective heat transfer coefficient, } \\
& \mathrm{W} \mathrm{m}^{-2} \mathrm{~K}^{-1}\end{aligned}$ \\
\hline $\mathrm{H}$ & $=$ height, $\mathrm{m}$ \\
\hline I & $=$ local solar irradiation, $\mathrm{W} \mathrm{m}^{-2}$ \\
\hline $\mathrm{k}$ & $=$ thermal conductivity, $\mathrm{W} \mathrm{m}^{-1} \mathrm{~K}^{-1}$ \\
\hline 1 & $\begin{aligned}= & \text { volume element side (length, width, or } \\
& \text { height), } \mathrm{m} \text {; distance between VE centers }\end{aligned}$ \\
\hline $\mathrm{L}$ & $=$ length, $\mathrm{m}$ \\
\hline $\mathrm{m}$ & $=$ mass, $\mathrm{kg}$ \\
\hline$\dot{\mathrm{m}}$ & $\begin{aligned}= & \text { mass flow rate, } \mathrm{kg} \mathrm{s}^{-1} \text {; external mass flow } \\
& \text { rate, } \mathrm{kg} \mathrm{s}^{-1}\end{aligned}$ \\
\hline $\mathrm{n}$ & $=$ total number of VE; material type number \\
\hline $\mathrm{n}_{\mathrm{eq}}$ & $\begin{aligned}= & \text { total number of equipment cooled } \\
& \text { internally in a zone }\end{aligned}$ \\
\hline NTU & $=$ number of heat transfer units \\
\hline $\mathrm{p}_{\mathrm{v}}$ & $=$ vapor pressure, $\mathrm{N} \mathrm{m}^{-2}$ \\
\hline $\mathrm{p}_{\mathrm{vs}}$ & $=$ water vapor saturation pressure, $\mathrm{N} \mathrm{m}^{-2}$ \\
\hline $\operatorname{Pr}$ & $=$ Prandtl number \\
\hline$q$ & $=$ heat transfer rate (regenerator), $\mathrm{W}$ \\
\hline$\dot{\mathrm{Q}}$ & $=$ heat transfer rate, $\mathrm{W}$ \\
\hline $\mathrm{R}$ & $\begin{aligned}= & \text { thermal resistance, } \mathrm{m}^{2} \mathrm{KW}^{-1} \\
& \text { stoichiometric relation }\end{aligned}$ \\
\hline $\mathrm{Ra}$ & $=$ Rayleigh number \\
\hline $\operatorname{Re}$ & $=$ Reynolds number \\
\hline $\mathrm{S}$ & $=$ surface area, $\mathrm{m}^{2} \phi$ \\
\hline$S^{\varphi}$ & $=$ source term referring to physical quantity $\phi$ \\
\hline $\mathrm{t}$ & $=$ time, $\mathrm{s} ;$ thickness, $\mathrm{m}$ \\
\hline $\mathrm{T}$ & = temperature, $\mathrm{K}$; external fluid temperature, $\mathrm{K}$ \\
\hline $\mathrm{U}$ & $\begin{aligned}= & \text { overall heat transfer coefficient, } \\
& \mathrm{W} \mathrm{m} \mathrm{m}^{-2} \mathrm{~K}^{-1}\end{aligned}$ \\
\hline $\mathrm{V}$ & $=$ velocity, $\mathrm{m} \mathrm{s}^{-1}$ \\
\hline var & $=$ variable \\
\hline $\mathrm{V}$ & $=$ volume, $\mathrm{m}^{3}$ \\
\hline $\mathrm{x}, \mathrm{y}, \mathrm{z}$ & $=$ Cartesian coordinates, $\mathrm{m}$ \\
\hline $\mathrm{Y}$ & $=$ mass fraction \\
\hline
\end{tabular}

\section{Greek letters}

\footnotetext{
$\alpha \quad=$ absorptivity; specific heat ratio

$\alpha_{\mathrm{T}}$
}

convective heat transfer coefficient,

$=$ height, $\mathrm{m}$

$=$ thermal conductivity, $\mathrm{W} \mathrm{m}^{-1} \mathrm{~K}^{-1}$

volume element side (length, width, or

$=$ length, $\mathrm{m}$

mass flow rate, $\mathrm{kg} \mathrm{s}^{-1}$; external mass flow

$=$ total number of VE; material type number

total number of equipment cooled

number of heat transfer units

= vapor pressure, $\mathrm{N} \mathrm{m}^{-2}$

$=$ Prandtl number

$=$ heat transfer rate, $\mathrm{W}$

thermal resistance, $\mathrm{m}^{2} \mathrm{~K} \mathrm{~W}^{-1}$;

Rayleigh number

$=$ source term referring to physical quantity $\phi$

= time, $\mathrm{s}$; thickness, $\mathrm{m}$

overall heat transfer coefficient,

$=$ variable

$=$ Cartesian coordinates, $\mathrm{m}$

mass fraction

\begin{tabular}{|c|c|}
\hline $\mathrm{a}$ & $=$ number of adjacent VEs \\
\hline $\mathrm{adv}$ & $=$ advection \\
\hline ar & = wire \\
\hline asw & $=$ auxiliary external flow \\
\hline $\mathrm{b}$ & $=$ bottom \\
\hline $\mathrm{c}$ & $=$ number of solid $\mathrm{VE}$ \\
\hline cond & $=$ conduction \\
\hline conv & $=$ convection \\
\hline $\mathrm{cw}$ & $=$ chilled water unit \\
\hline dif & $=$ diffusion \\
\hline DCS & $=$ dedicated cooling system \\
\hline e & $=$ east \\
\hline eq & $=$ equivalent \\
\hline ext & $=$ exterior \\
\hline evap & $=$ evaporator \\
\hline $\mathrm{E}$ & $=$ inlet \\
\hline f & $=$ fluid \\
\hline fan & $=$ fan \\
\hline film & $=$ film \\
\hline free & $=$ free \\
\hline fw & $=$ internal fluid \\
\hline g & $=$ metal grid in the regenerator \\
\hline gen & $=$ generation in $\mathrm{a} \mathrm{VE}$ \\
\hline gl & $=$ grid side \\
\hline gs & $=$ grid cross section \\
\hline $\mathrm{gt}$ & $=$ inner tube annulus \\
\hline $\mathrm{hx}$ & $=$ heat exchanger \\
\hline i & $=$ number of VE \\
\hline in & $=$ inlet \\
\hline int & $=$ interior \\
\hline j & $=\mathrm{VE}$ face; VE number \\
\hline $\mathrm{k}$ & $=\mathrm{VE}$ face; VE number \\
\hline $\mathrm{L}$ & $=$ length \\
\hline 1 & $=\mathrm{VE}$ face \\
\hline $\mathrm{m}$ & $=$ direction; mesh \\
\hline $\max$ & $=$ maximum \\
\hline $\min$ & $=$ minimum \\
\hline $\mathrm{n}$ & $=$ north \\
\hline neigh & $=$ neighbor \\
\hline other & $=$ other interaction \\
\hline
\end{tabular}

\section{Subscripts}

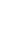

$=$ volumetric thermal expansion coefficient, $\mathrm{K}^{-1}$

$=$ surface area ratio, Eqn. (55)

$=$ distance between VE centers (regenerator)

= emissivity; effectiveness, Eqn. (28)

$=$ heat exchanger effectiveness

$=$ relative mesh refinement error

$=$ thermal efficiency

$=$ reaction rate, $\mathrm{s}^{-1}$

$=$ kinematic viscosity, $\mathrm{m}^{2} \mathrm{~s}^{-1}$

$=$ density, $\mathrm{kg} \mathrm{m}^{-3}$

$=$ Stefan-Boltzmann constant, $5.6731028 \mathrm{~W} \mathrm{~m}^{-2} \mathrm{~K}^{-4}$

$=$ general scalar field; porosity

$=$ relative humidity 


\begin{tabular}{|c|c|}
\hline $\mathrm{p}$ & $\begin{aligned}= & \text { gas at constant pressure; } \\
& \text { posterior; insulation }\end{aligned}$ \\
\hline $\mathrm{q}$ & $=$ species in a mixture \\
\hline r & $=$ internal fluid (regenerator) \\
\hline $\mathrm{rad}$ & $=$ radiation \\
\hline reg & $=$ steady state, regime \\
\hline $\mathrm{R}$ & $=$ real \\
\hline S & $=$ south \\
\hline SW & $=$ external fluid \\
\hline swhx & $=$ seawater heat exchanger \\
\hline $\mathrm{t}$ & $=$ top; inner tube (regenerator) \\
\hline tot & $=$ total \\
\hline $\mathrm{tl}$ & $=$ lateral side of the tube \\
\hline $\mathrm{T}$ & $=$ total \\
\hline $\mathrm{W}$ & = west; wall \\
\hline $\mathrm{x}$ & $=\mathrm{x}$-direction \\
\hline $\mathrm{y}$ & $=\mathrm{y}$-direction \\
\hline $\mathrm{Z}$ & $=\mathrm{z}$-direction \\
\hline 0 & $=$ initial condition \\
\hline$\infty$ & $=$ external air \\
\hline$|\cdot|$ & $=$ absolute value \\
\hline$\|\cdot\|$ & $=$ Euclidean norm \\
\hline
\end{tabular}

\section{ACKNOWLEDGEMENT}

This work was supported through the Office of Naval Research (ONR), grant N00014-08-1-0080.

\section{REFERENCES}

1. Hall AD. A Methodology for Systems Engineering. Van Nostrand: New York, 1962.

2. Sage AP. Systems Engineering. Wiley: New York, 1992.

3. Honour E. INCOSE: history of the International Council on Systems Engineering. The Journal of the International Council on Systems Engineering 1998; 1:4-13.

4. Woods RL, Lawrence KL. Modeling and Simulation of Dynamic Systems. Prentice-Hall: Upper Saddle River, NJ, 1997.

5. Vargas JVC, Stanescu G, Florea R, Campos MC. A numerical model to predict the thermal and psychrometric response of electronic packages. ASME Journal of Electronic Packaging 2001; 123(3):200-210.

6. Shapiro B. Creating compact models of complex electronic systems: an overview and suggested use of existing model reduction and experimental system identification tools. IEEE Transactions on Components and Packaging Technologies 2003; 26(1):165-172.

7. Trivelato GC. Técnicas de modelagem e simulação de sistemas dinámicos. Ministério da Ciência e
Tecnologia, Instituto Nacional de Pesquisas Espaciais -INPE: São José dos Campos, Brazil, 2003.

8. Kaiser KL. Electromagnetic Compatibility Handbook. CRC Press: Boca Raton, FL, 2004.

9. Lall P, Islam MN, Rahim MK, Suhling JC. Prognostics and health management of electronic packaging. IEEE Transactions on Components and Packaging Technologies 2006; 29(3):666-677.

10. Gnanasambandam N, Primavera A, Srihari KN. The reliability prediction of electronic packages - an expert systems approach. International Journal of Advanced Manufacturing Technology 2005; 27(3-4):381-391.

11. Bagnoli PE, Padovani C, Pagni A, Pasquinelli G. A thermomechanical solver for multilayer power electronic assemblies integrated into the DJOSER thermal simulator. Journal of Electronic Packaging 2011; 133(1):011005.

12. Yang $\mathrm{P}$, Chen ZX. Testing on dynamic behavior of PBGA assembly by considering fixed-modes. Microelectronics International 2011; 28(2):23-29.

13. Ordonez JC, Vargas JVC, Hovsapian R. Modeling and simulation of the thermal and psychrometric transient response of all-electric ships, internal compartments and cabinets. Simulation 2008; 84(8-9):427-439.

14. Dias FG, Souza JA, Ordonez JC, Vargas, JVC, Hovsapian R, Amy JR. Notional all-electric ship thermal simulation and visualization. Proceedings of the 2009 IEEE Electric Ship Technologies Symposium, Baltimore, Maryland, 2009 ESTS Proceedings, New York, IEEE, 2009.

15. Vargas JVC, Souza JA, Hovsapian R, Ordonez JC, Chiocchio T, Chalfant J, Chryssostomidis C, Dilay E. Notional all-electric ship systems integration thermal simulation and visualization. Simulation: Transactions of the Society for Modeling and Simulation International 2012; 88(9):1116-1128.

16. Dilay E, Vargas JVC, Ordonez JC, Yang S, Schrattenecker R, Coleman M, Chiocchio T, Chalfant J, Chryssostomidis C. The experimental validation of a transient power electronic building block (PEBB) mathematical model. Applied Thermal Engineering 2013; 60(1-2):411-422.

17. Song ZH, Murray BT, Sammakia B. A compact thermal model for data center analysis using the zonal method. Numerical Heat Transfer Part A -Applications 2013; 64(5):361-377. doi:10.1080/ 10407782.2013.784138.

18. Boukhris Y, Gharbi L, Ghrab-Morcos N. Simulating air flow, with a zonal model, for natural convection in a partitioned dwelling. International Journal of Ventilation 2008; 7:207-219.

19. Boukhris Y, Gharbi L, Ghrab-Morcos N. Modeling coupled heat transfer and air flow in a partitioned 
building with a zonal model: application to the winter thermal comfort. Building Simulation 2009; 2:67-74.

20. Song F, Zhao B, Yang X, Jiang Y, Gopal V, Dobbs G, Sahm M. New approach on zonal modeling of indoor environment with mechanical ventilation. Building and Environment 2008; 43:278-286.

21. Prigogine I, Kondepudi D. Thermodynamique. Chapter 2. Éditions Odile Jacob: Paris, 1999.

22. Bejan A. Advanced Engineering Thermodynamics. Wiley: New York, 1988.

23. Fletcher CAJ. Computational Techniques for Fluid Dynamics, Vol. 1. Springer-Verlag: Berlin, 1991.

24. Martins LS, Ordonez JC, Vargas JVC, Parise JAR. Thermodynamic optimization of a regenerator heat exchanger. Applied Thermal Engineering 2012; 45:42-51.

25. Kays WM, London AL. Compact Heat Exchangers (3rd). Krieger Publishing Company: Malabar, FL, 1998.

26. Duffie JA, Beckman AA. Solar Energy Thermal Processes. Wiley: New York, 1974; 34-37.

27. Churchill SW, Chu HHS. Correlating equations for laminar and turbulent free convection from a vertical plate. International Journal of Heat and Mass Transfer 1975; 18:1323-1329.

28. Bejan A. Heat Transfer. Wiley: New York, 1993.

29. Bejan A. Convection Heat Transfer (2nd). Wiley: New York, 1995.

30. Kincaid D, Chenney W. Numerical Analysis. Wadsworth: Belmont, CA, 1994.

31. Editorial Board. Journal of Heat Transfer Editorial Policy Statement on Numerical Accuracy. ASME Journal of Heat Transfer 1994; 116:797-798.

32. Minkowycz WJ, Sparrow EM, Schneider GE, Pletcher RH. Handbook of Numerical Heat Transfer (2nd). Wiley: New York, 2006.

33. Amy J. Load analysis 2007 for ESRDC3 REV2.xls. Electric Ship Research and Development Consortium, 2008.

34. Dilay E, Vargas JVC, Ordonez JC, Hovsapian R, Chalfant J, Chryssostomidis C. A mesh generation strategy for representing hull geometry in ESRDC ship thermal simulation and visualization. Proceedings of the 2012 Grand Challenges in Modeling and Simulation, Genoa, Italy, GCMS Proceedings, 2012. 